\title{
Interdependence of friction, wear, and noise: A review
}

\author{
Kevin LONTIN*, Muhammad KHAN \\ Cranfield University, MK43 OAL, UK \\ Received: 02 July 2020 / Revised: 02 November 2020 / Accepted: 29 January 2021 \\ (C) The author(s) 2021.
}

\begin{abstract}
Phenomena of friction, wear, and noise in mechanical contacts are particularly important in the field of tribomechanics but equally complex if one wants to represent their exact relationship with mathematical models. Efforts have been made to describe these phenomena with different approaches in past. These efforts have been compiled in different reviews but most of them treated friction, wear mechanics, and acoustic noise separately. However, an in-depth review that provides a critical analysis on their interdependencies is still missing. In this review paper, the interdependencies of friction, wear, and noise are analysed in the mechanical contacts at asperitical level. The origin of frictional noise, its dependencies on contact's mechanical properties, and its performance under different wear conditions are critically reviewed. A discussion on the existing mathematical models of friction and wear is also provided in the last section that leads to uncover the gap in the existing literature. This review concludes that still a comprehensive analytical modelling approach is required to relate the interdependencies of friction, noise, and wear with mathematical expressions.
\end{abstract}

Keywords: noise; acoustic emission; wear; friction

\section{Introduction}

Wear processes present a severe challenge in industry. This is because wear reduces the useful life of machine components and thus, replacing machine components prove costly [1]. The friction of worn-out surfaces of these components does have an influence on the wear processes. The mechanism of these processes mainly depends on mechanical properties and physical geometries of the surfaces in contact and the type of load applied [2]. However, changes in these processes have been rigorously observed in the past with the help of the emitted noise generated at the point of contact $[3,4]$. For example, the calculation of the sound pressure can be performed by the Boundary Element Method at a high computational cost [5]. This is due to the high number of harmonic components associated with the friction-induced vibrations. Efforts have been made to reduce the computational cost associated with the Boundary Element Method by performing partial computations using only the dominant harmonic components as opposed to full harmonic components though they remain more costly than Finite Element Methods [6]. The studies of acoustic emissions are mostly done on disc brake systems as this is an area of industry where noise reduction is especially important for the consumers. However, most of these past efforts are based on empirical relationships [7].

More often, these relationships are accurate in labbased experiments and generate wear measurements under real operating conditions [8]. For instance, wear occurring under unlubricated conditions can be readily measured and extended in practical applications outside of the lab. Furthermore, many wear processes can also be reasonably explained and then applied in industrial applications. However, their accuracy remains in question when machines with several worn-out components are under investigation or when more complex situations arise (such as the use of lubrication). This is because integrating all the

* Corresponding author: Kevin LONTIN, E-mail: K.Lontin@cranfield.ac.uk 
different mechanisms by which wear occurs into a unified wear model is problematic. Various mathematical models have been developed to account for friction and its relationship with wear [9]. Combining friction models with wear models is important because, along with heat generation, the way frictional work dissipates is linked to roughness changes, wear particle generation, tribomaterial evolution, and microstructural alterations [10]. Having an identical friction coefficient does not necessarily indicate that the friction processes will be similar [11]. This is because the difference in the generation of wear can drastically alter the friction processes too. This might not be the case when the sliding distance is low, or the applied load is low or if the materials have been effectively lubricated. However, in most other cases, the mechanisms of wear generation will influence the frictional processes and those should be examined by embedding wear models into friction models. However, in these models, the acoustic emissions and the airborne noise are not included, which means that two fundamental components generated during the friction processes are still missing. Hence, they do not describe the true physics and interdependencies of friction, noise, and wear altogether.

Different reviews have been published on friction and friction-induced noise. Akay [12] published a review on various noise generation mechanisms that occur due to different friction processes. The review does not consider how the noise mechanisms will differ as wear starts to develop. Similarly, Pennestrì et al. [13] published a review on the most widespread friction models. They found most of these models are empirical by nature and they do not take wear into account. In industrial applications, Archard's wear model remains the most widely used model. Most of those are based on experimental evidence [14] and hence analytical work on friction and wear remains scarce.

So far, the published reviews treated friction, wear mechanics, and acoustic noise separately and an in-depth review that provides a critical analysis on their interdependencies is still missing. This review paper aims to provide a critical analysis on the existing friction, wear, and acoustic models and highlight the existing interdependencies between them. To get a fundamental understanding of the generation of wear and friction noise, this review first examines the mechanisms of contact at asperitical level. Then, a critical review of how the frictional noise is altered due to the contact's mechanical properties under different wear conditions is provided. Finally, a survey of the existing friction and wear models is provided in the last section. This review will help to uncover the existing research gap. As of now, despite the interdependencies of friction, wear, and noise being established, a comprehensive analytical model that incorporates all three of those components still has not been developed. A unified mathematical model that incorporates friction, wear, and noise could be a significant contribution to scientific knowledge as well as of significant practical use in industry, most notably in wear monitoring.

\section{Concept of asperities and area of physical contact}

The idea of the multi-asperitical contacts was first published by Bowden et al. [15]. They introduced the fact that friction between two rough surfaces is caused by the contact between the peak asperities i.e., Antagonist asperities. This shows that the actual area of contact, which is the area of contact between the asperities of both the surfaces, is vastly different from the apparent area of contact as shown in Fig. 1.

Coulomb's first law of friction agrees as it states that the friction force is independent of the apparent area of contact but dependant on the actual area of contact [16]. In Bowden and Tabor's model, however, the number of asperities was assumed to be constant. Archard [17] refined the model by introducing a

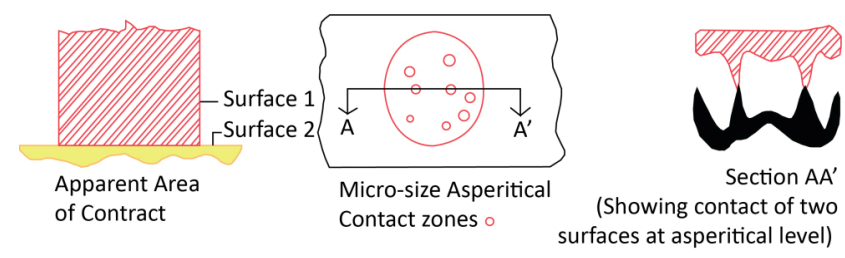

Fig. 1 Apparent area of contact and real area of contact. (a) represents the area of contact as seen from a macroscopic point of view, (b) and (c) represent the contact area from a microscopic point of view, where the contact depends on the asperities located on both surfaces. (b) shows a top-down view, while (c) shows a cross-sectional view. Reproduced with permission from Ref. [18], (C) CRC 2004. 
load-dependant number of asperities instead of a constant number. Greenwood and Williamson [19] further refined the model by introducing a Gaussian and an exponentional distribution of asperities.

The molecular attraction between these asperities is one of the fundamental principles of friction and adhesive wear both for metals and polymers [20, 21]. Different models have been developed to determine the contact adhesion. The Johnson-Kendall-Roberts (JKR) model uses a modified Hertz model to account for the surface energy that causes attraction between the two surfaces in elastic solids. This is shown in Fig. 2. However, the solids must be perfectly smooth. The deformation caused by the attractive forces are so small that the surface roughness interferes a lot with the measurements. This model agreed with experimental results for soft surfaces such as rubber and gelatine, which, if pressed together, deform to such an extent that the surface roughness becomes negligible by comparison. Such is not the case with metals [22]. Another model (the DMT model) was developed to determine the influence of the contact deformation and the molecular attraction between a ball and a plane [23]. As the ball enters contact with the plane, the molecular van der Waal's forces increase the contact area as the forces are attractive. The adhesion force was found to be proportional to the work done per unit area required in breaking the contact between the two surfaces. However, even though the contact area increases due to the van der

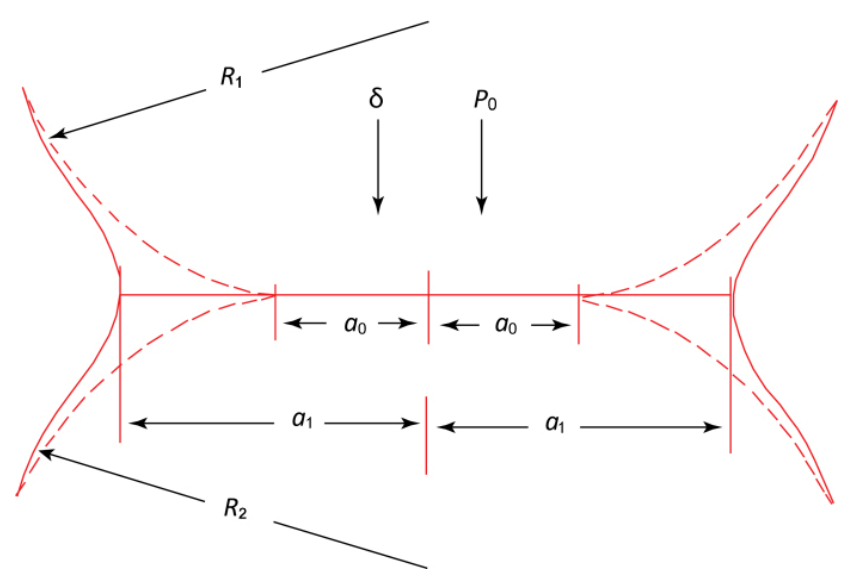

Fig. 2 Contact between two elastic solids both in the presence (contact radius $a_{1}$ ) and absence (contact radius $a_{0}$ ) of surface forces. Reproduced with permission from Ref. [22], (C) Royal Society Publishing 1971.
Waal's forces, the force required in breaking up the contact does not increase. It can thus be calculated from the non-deformed contact.

Where $R_{1}$ and $R_{2}$ are the radius of the spheres, $\delta$ is the elastic displacement due to the surface forces and $P_{0}$ is the applied load. Another comparative analysis was done by Johnson and Greenwood [24]. It was shown that the JKR adhesion theory was valid for large spheres more suited to polymers whereas the DMT theory was more suited for small, micrometresized metals spheres, which are elastic. An improved model to account for the transition was also developed [25]. It uses the Lennard-Jones potential to show that the magnitude of the force required to separate the two surfaces varied continuously between the surfaces described by the JKR model and those described by the DMT model. The Lennard-Jones potential is shown in Fig. 3.

The area of contact influences the surface roughness and thus, the generation of friction noise [26]. Simulations were also performed to correlate the real contact area with the surface roughness parameters $[27,28]$. The effect of wear particles during the friction processes would influence the actual area of contact [29] as shown in Fig. 4.

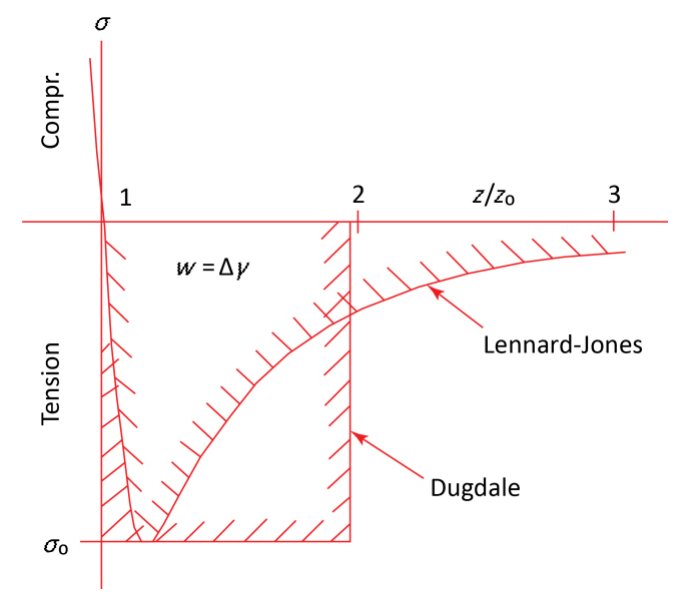

Fig. 3 Lennard-Jones potential and the Dugdale approximation. Reproduced with permission from Ref. [25], (C) Elsevier 1994. Where $\sigma=$ force, $\sigma_{0}=$ maximum tensile force, $w=$ work of adhesion, $\gamma=$ surface energy, and $z=$ separation between the two planes and $z_{0}=$ equilibrium separation. There are no hysteresis forces that would cause permanent deformation. In the case of hysteresis, the work required to break apart the two surfaces is greater than the energy restored when the two surfaces come together. 


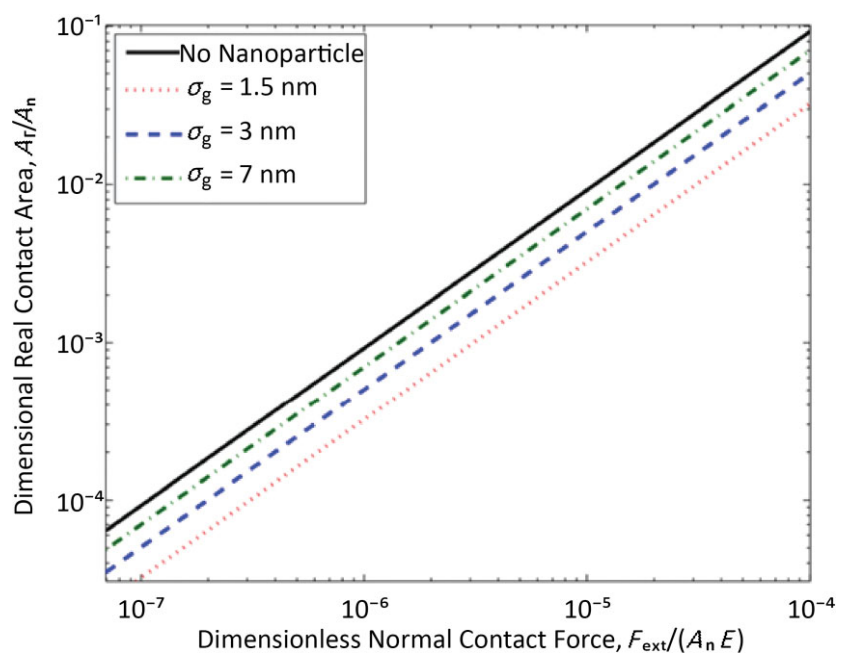

Fig. 4 Effect of average particle size on real contact area. Reproduced with permission from Ref. [29], C ASME 2013.

As the average size of the particles increase, the real contact area decreases. A decrease in the real area of contact introduces a decrease in friction. This is because the wear particles help in keeping the surfaces out of contact. However, there is a point of saturation. If the number of intermediate particles reaches the saturation point, then this leads to an increase in friction. The results were found to hold for abrasive wear particles only and it is not certain it would hold for other types of wear. The frictional heat generated by two surfaces under friction can provide an estimate for the real area of contact [30]. Assuming that the frictional heat power is constant, the measured temperature can be used as a constraint in a finite element model to determine the contact area as shown in Fig. 5.

The contact area increases due to an increase in the load and/or the sliding speed. However, the model used to calculate the contact area has some limitations.
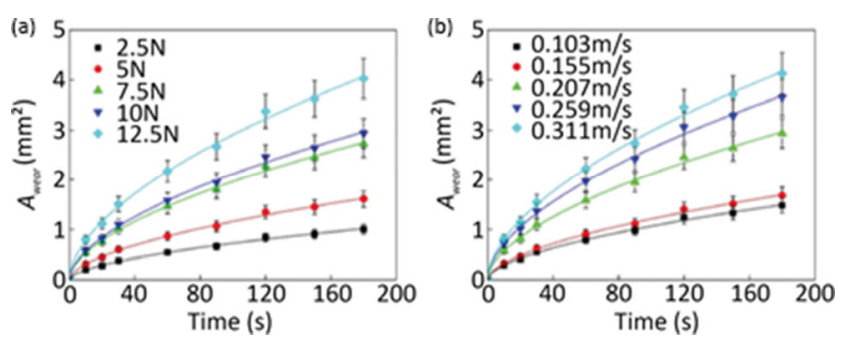

Fig. 5 Wear area curve-fit result. (a) Load effect on wear area at a constant sliding speed of $0.207 \mathrm{~m} / \mathrm{s}$; (b) sliding speed effect on wear area at a constant load of $10 \mathrm{~N}$. Reproduced with permission from Ref. [30], (C) AIP Publishing LLC 2016.
For example, it is only suitable for dry friction. In case of mixed/lubricated friction, the contact area effectively becomes zero. This is because the thermocouple requires conductance between the two surfaces. If the surfaces are not conductive or if there is a lubricant interference with the thermocouple, then this method fails.

Song and Yan [31] investigated the relationship between the real area of contact and the contact force during the pre-sliding regime. A tangential load was applied to the contact interface in quasi-static state, and the magnitude of the static friction was obtained and correlated with the real contact area. The increasing quantity of the interconnecting asperities was proven to be the dominant factor that expands the real contact area. It also expands linearly with the increase in static friction under a constant normal pressure in the pre-sliding regime. As the normal pressure increases and the static friction decreases, the real contact also changes.

The research shows that the real contact area is highly dependent on the number of asperities that are contacting on both surfaces. However, so far, there is no conclusive research as to how the number of contacting asperities will change with the change of friction or wear processes. To understand how the asperities and the change in asperitical contacts will influence the wear and the friction processes, it is necessary to investigate the friction processes at the microscopic level.

\section{Relationship between friction and wear at the microscopic level}

Although wear can be measured from a macroscopic point of view, the physical area of contact is particularly important to quantify the relationship between the wear and the friction. As such, it is necessary to go down to asperitical levels. At those levels, there are two main wear mechanisms that take place: adhesive wear and abrasive wear. Adhesive wear is caused when the contact between the two antagonist asperities has enough intermolecular attraction so that the asperities resist the sliding or demonstrate friction. The contact region of the asperities dislocates under compression and shearing [32]. A crack is initiated 
and propagated, and a wear particle is formed when the crack reaches the contact interface. The wear particle may then adhere to one of the surfaces as shown in Fig. 6.

Abrasive wear occurs when the hardness of one asperitical surface is higher than the other as shown in Fig. 7. This causes one surface to plough through the other. This mechanism resists the possible sliding, and this shows the impact that friction has

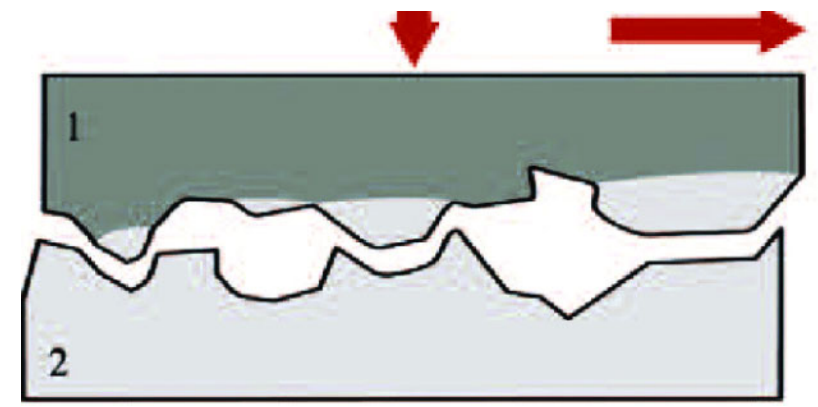

Fig. 6 Adhesive wear mechanism.

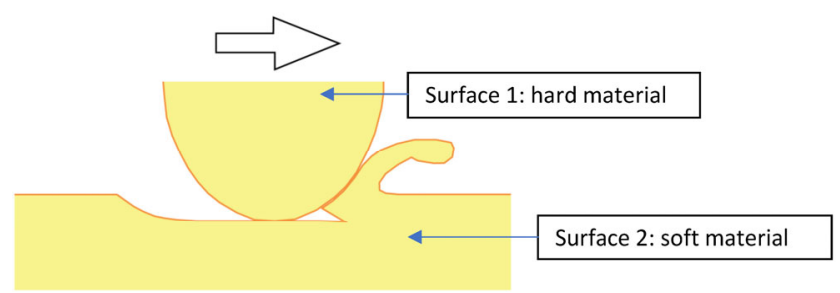

Fig. 7 Abrasive Wear mechanism. in abrasive wear. There are three different abrasive wear modes: microcutting, wedge-forming, and ploughing as shown in Fig. 8. Under low friction, microcutting is more common. Higher friction will cause wedge-forming [33].

Several experimental and numerical studies have been performed to describe the details of the relationship between friction and wear. Aghababaei et al. [34] studied the correlation between the microscopic wear debris generated between two asperities on contacting surfaces. They performed simulations consisting of millions of atoms under friction-based contact with different sizes, and boundary conditions as shown in Fig. 9. The volume of wear debris generated was found to be proportional to the tangential work done on the surfaces (that is, the product of the tangential force applied and the sliding distance). However, there were no correlations found between the volume of the wear debris generated and the normal force applied at the debris level.

Myshkin and Kovalev [21] developed a precision tribometer with a normal load range from $1 \mathrm{mN}$ to $1 \mathrm{~N}$ and velocity range from 0.1 to $10 \mathrm{~mm} / \mathrm{s}$. They conducted an experiment using a steel 52100 ball against a silicon substrate. The friction coefficient was then plotted against the number of cycles as shown in Fig. 10. (a)

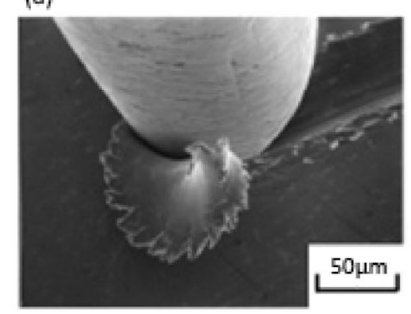

(b)

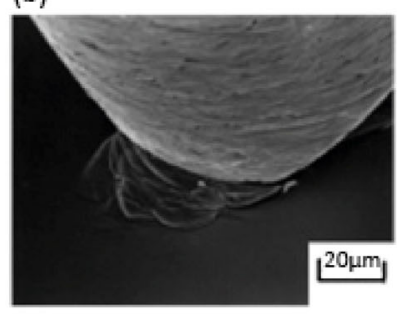

(c)

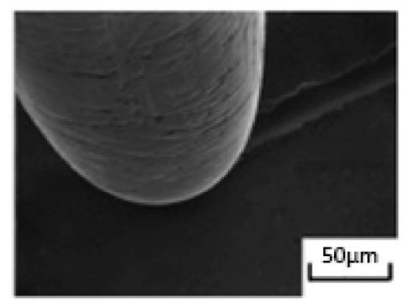

Fig. 8 SEM images of the abrasive wear modes: (a) microcutting, (b) wedge-forming, and (c) ploughing. Reproduced with permission from Ref. [33], (C) CRC Press 2001.
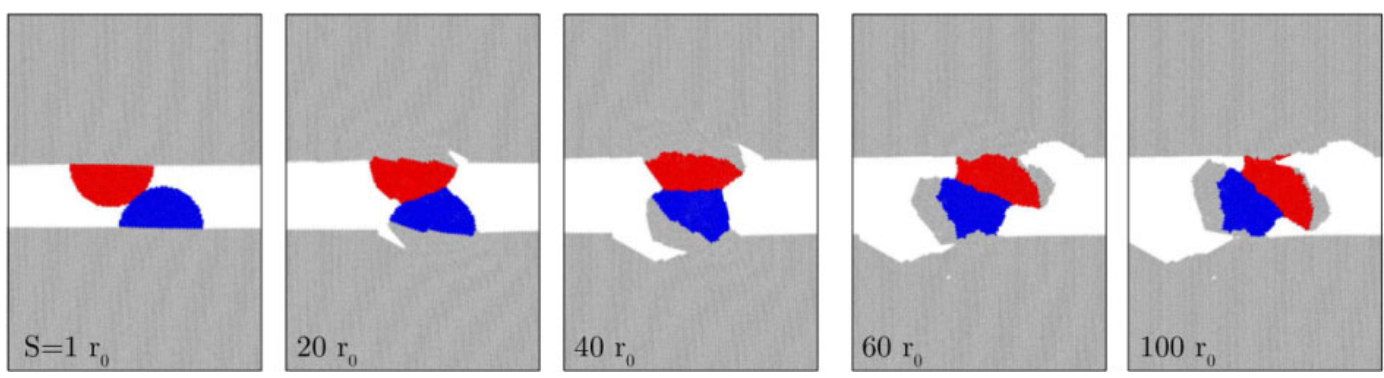

Fig. 9 Debris formation at the asperity level. Reproduced with permission from Ref. [34], (c) PNAS 2017. 


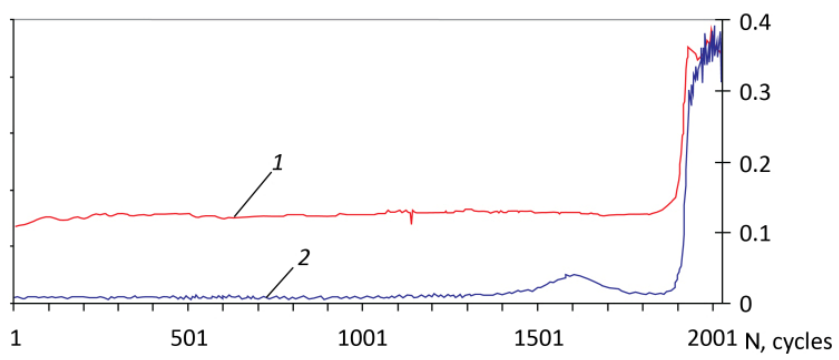

Fig. 10 Friction coefficient vs. number of test cycles. Reproduced with permission from Ref. [21], C) Imperial College Press 2009. Where "2" in Fig. 10 shows the results with the material coated in the SEBS (Styrene Ethyl butylene Styrene) coating, and "1" in Fig. 10 shows the material with no coating. There is a large increase in the friction coefficient. This implies that wear develops as the number of cycles increases.

However, to comprehend how the friction processes and the wear that ensue lead to the generation of friction noise, it is necessary to go down to asperitical level. At such levels, the contact parameters become a lot more important. These include the properties of the contacts as well as their geometries. How those influence the asperity distributions will lead to changes in the vibrations and the sound generation.

\section{Origin of friction noise and its depen- dencies on contact mechanical properties and geometries}

Friction noise is generated during any friction process. Friction transmits energy from one surface to another as well as dissipating energy of relative motion. On the microscale, friction converts kinetic energy to thermal energy and thus acts as a dissipation mechanism. This process involves the oscillations of atoms. As we go to asperitical levels, if the system supplies more energy that can be dissipated, an instability is observed, which results in the generation of friction sound [35]. Friction sounds are unsteady and transient and depend on many different factors. Friction sound can emanate from one or both components of the friction pair or from some other parts of the system.

Fundamentally, during the sliding processes, the influence of the contact force reaches beyond the contact interface. The friction pair becomes a coupled system and the friction-induced vibrations caused by system instabilities resonate at their fundamental frequencies and harmonics. For example, in the typical wine glass example, the glass will resonate at its fundamental frequency when a wetted finger passes on the rim. Spurr [36] performed an experiment that showed that the wine glass had a dominant vibrational frequency that corresponded to its natural frequency. This is shown in Fig. 11.

The ring had a strong peak at about 1,150 cps. The other peaks were at integral multiples of this frequency. This corresponds to the different modes of the natural frequency.

The instabilities that result in the generation of friction sound can be caused by several different mechanisms. They can be related to geometric instabilities, to the material non-linearities, to instabilities caused by decreasing friction, which occurs in increasing velocities or they can be caused by thermoelastic instabilities [37]. Those instabilities are created because of a variation in contact forces that occur in a system. One notable example would be disc-brake systems. The contact forces will change as the disc is worn out or as the disc expands as heat is generated. Both those factors will contribute to the reduced effectiveness of the brake system; thus, mitigation of the heat generation and the wear generation is important.

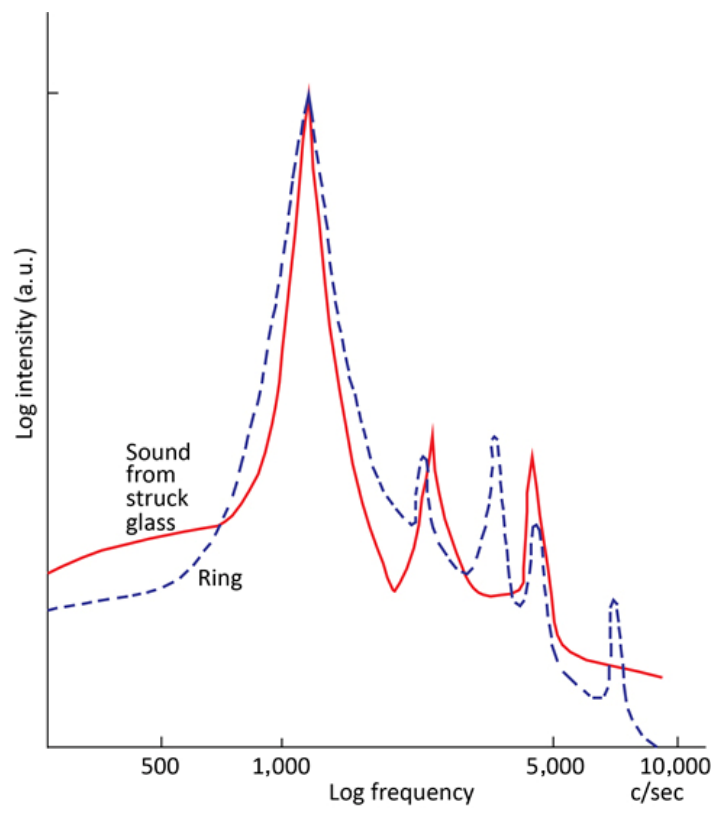

Fig. 11 Frequency spectra of ring and of sound emitted by struck glass. Reproduced with permission from Ref. [36], C Elsevier 1961. 
The generation of friction noise mostly depend on the variation of the contact forces at the interface, which will influence the contact area. Those are dependent on the properties of the contact interface. For instance, an elastic material such as rubber can result in large deformation when a contact force is applied. This will result in a large contact area and that will lead to a certain sound spectrum. Conversely, a hard material like steel will not deform like rubber when the contact force is applied. The contact area would therefore be different and thus, the sound generation will also be different [38]. For example, one major area of study is in the disc brake systems and the squeal noise generated. Kinkaid et al. [39] provided a comprehensive review of the different models that could explain squeal generation in brake systems. Müller and Ostermeyer [40] extended the two-dimensional cellular automaton model to create a three-dimensional cellular automaton model to describe the interdependencies of friction and wear in brake systems. The topography of the brake pads changes based on the temperatures and pressure along with the external load applied. Based on those measurements and the Cellular Automata simulations, the interdependencies between the friction and the wear of the brake pads can be established. An increase in the load causes a higher surface roughness profile and higher contact areas up until a certain point. Further increases in the load no longer alters the topography much. Ostermeyer [41] also further investigated the lateral dynamics of brake systems under wear. Due to the increasing local normal and tangential stresses occurring around the areas where the wear particles are formed, the temperature also increases. This may lead to an alloying process between the hard particle and the wear particle, causing the formation of contact patches and different contact zones (the polymeric matrix for the brake material and the generated hard patches). The relationship between the friction and the wear will therefore depend on several factors which include the number and size of the contact patches as well as the temperature generated during the friction processes. Nishiwaki et al. [42] examined the possibilities of brake squeal reduction by refining not only the brake structures but also the materials of the brake pads. Two prototypes' materials were used as test prototypes, phenol formaldehyde resin, and polyamideimide (PAI). 500 tests were performed, and it was found that brake squeal occurred in $84 \%$ of the tests when the phenol formaldehyde resin binder was used. Conversely, brake squeal occurred in only $40 \%$ of the tests when the PAI binder was used. This is because one mechanism responsible for squeal is the variation of the friction coefficient. Replacement of the brake pad material leading to a smaller variation of the friction coefficient will result in less squeal noise. Chen and Bogy [43] created a numerical model for the interaction and friction forces on a hard drive system (the readheard sliding on the magnetic disk). A pin-on-disk experiment was conducted by Earles and Lee [44] to validate their theoretical analysis. The frictional noise generated by a pin-on-disk system is caused by the dominant vibrational mode of the pin-disk subsystem. The pin-disk system was modelled as a three-degrees of freedom model (parallel, normal, and rotational). Using this model, they could predict the regions of instabilities responsible for the squeal noise and it was validated experimentally.

This region of instability is called the kinematic constraint instability. Earles and Chambers [45] also studied how damping could be used to reduce the instability region. However, it was shown that damping could not reduce the magnitude of the instability.

Crolla and Lang [46] studied the effect of vibration induced noise on brake systems. They implemented an empirical approach on the modelling and design of brake systems as it was found that analytical solutions were not satisfactory and unfortunately did not meet industry requirements when it comes to squeal noise mitigation on the brake systems. They also focused on the commercial importance of reducing brake squeal noise due to growing customer complaints.

An analytical model was devised by Hervé et al. [47]. The model created was a two-degrees-of-freedom model which was linearized. The equations of motion for the linearized model near the equilibrium region can be written as follows:

$$
\boldsymbol{M} \ddot{\boldsymbol{X}}+\boldsymbol{D} \dot{\boldsymbol{X}}+\boldsymbol{K} \boldsymbol{X}=0
$$

where $M$ is the mass matrix, $D$ is the damping matrix, and $K$ is the stiffness matrix. 
Ibrahim [48] provided a comprehensive review and discussed the different mechanisms that would lead to the generation of friction-induced noise. These include stick-slip, variable dynamic friction coefficient, sprag-slip, and different coupling mechanisms. The sprag-slip model assumes that the coefficient of friction is unrelated to the sliding velocity. It emphasises the fact that the source of the instability is due to the geometry [49]. Other models that use a constant coefficient of friction were devised by Ouyang and Mottershead [50]. The chaotic behaviour of friction was also discussed in the stick-slip phenomenon. The behaviour in such a phenomenon is not smooth and thus non-smooth systems can lead to chaotic behaviour. Chatter and squeal in friction processes [51] were also investigated in sliding systems such as water-lubricated bearings in ships or submarines, wheel/rail systems, disc brake systems and machine tools. Chaos is a special form of squeal caused by non-linear forces and it is still not completely understood. Oberst and Lai [52] studied the chaotic behaviour of a nonlinear brake system. Godfrey [53] also studied the friction force on pin-on-disc setups and their oscillations. Different materials were tested along with different lubricating conditions. Results showed that the coefficient of friction varies with continued sliding as shown in Fig. 12.

Thus, it is more suitable to report the coefficient of friction as a range of values rather than a single nominal value. The friction oscillations varied because of the lubricating conditions. They were small for good lubricants and large for poor quality lubricants [54].

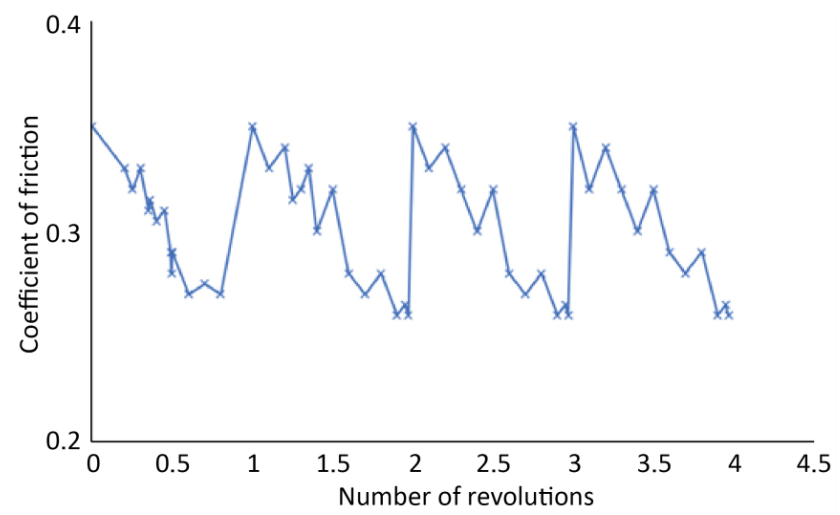

Fig. 12 Coefficient of friction measured during the sliding wear experiment. Reproduced with permission from Ref. [53], (C) Elsevier 1995.
Large material losses on the pin were associated with large friction oscillations while small material losses on the pin were associated with small friction oscillations. Further research including the surface roughness was performed by Yoon et al. [55].

Emira et al. [56] focused on the detection of stick-slip vibrations on a pin-on-disc experiment by using friction noise. The test rig was built so that the noise produced would be solely due to friction.

The stick-slip vibrations were predominant at high loads or high speeds. The characteristics of the noise produced can help to identify stick-slip vibrations as the spectrum of the noise includes high consecutive peaks. It can be easily seen as no noise is produced as stick occurs. This is shown in Fig. 13.

Stick-slip vibrations and chaos were also studied by Popp and Stelter [57] in which they studied selfexcitations due to dry friction and the transition from a regular to a chaotic motion. The parameter dependencies were also investigated. Both numerical and experimental methods were used, and two types of models were considered. Simpler discrete models were investigated numerically whereas more complex, continuous models were investigated experimentally. The experimental models could then be compared to the numerical models. Those would allow to get better evidence of chaotic behaviour and to develop enhanced analysis techniques for noise generation. Abdo et al. [58] and Chowdhury et al. [59] included the effect of humidity and the frequency of vibration on the amplitude of the stick-slip vibration. It was found that as the frequency increases, the amplitude of the vibrations decreases. Furthermore, humidity does have an impact at lower frequencies of vibrations, but they cease to have an impact after the frequency of vibrations reaches a higher value as shown in Fig. 14.

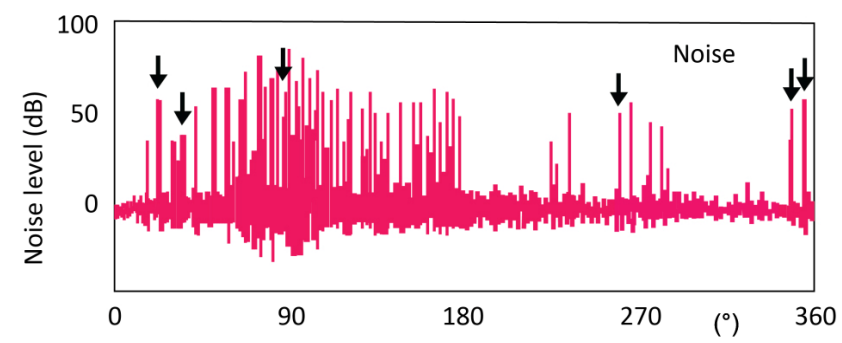

Fig. 13 Measured induced noise (steel pin, normal load $40 \mathrm{~N}$, $V_{\text {pin }}=5.2 \mathrm{~m} / \mathrm{s}$ ). Reproduced with permission from Ref. [56], (C) Academic Journals 2003. 


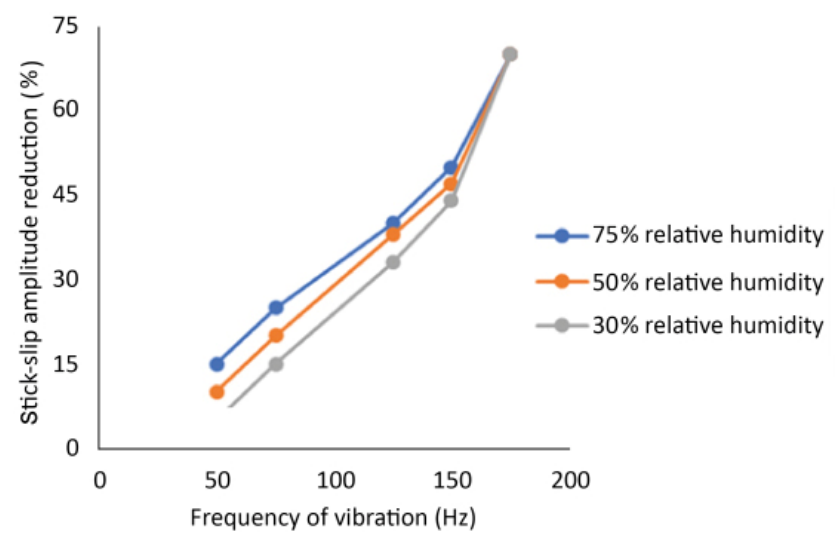

Fig. 14 Percentage reduction of stick-slip amplitude as a function of frequency of vibration with relative humidity. Reproduced with permission from Ref. [59], (C) Bentham Open 2008.

\section{Friction noise and contact geometries}

Even if the materials are similar, the geometry will also have an impact on the generation of sound. There have been numerical and experimental studies to determine how the geometry would affect the frictional noise. It is important to note that adhesive wear is a major component of sound. This is due to the wear debris accumulating between the two surfaces. However, changing the geometry of the surfaces will change the distribution of the wear debris. For example, groove textured surfaces reduce the impact of the wear debris because of the increased space between the two surfaces [60]. The geometry can otherwise increase the noise generation because it can lead to a larger contact area between the two surfaces.

In most numerical studies, the surfaces are assumed to be perfect. Hence, Bonnay et al. [61] created a methodology to introduce geometric imperfections into the contacts. For example, it was assumed that the

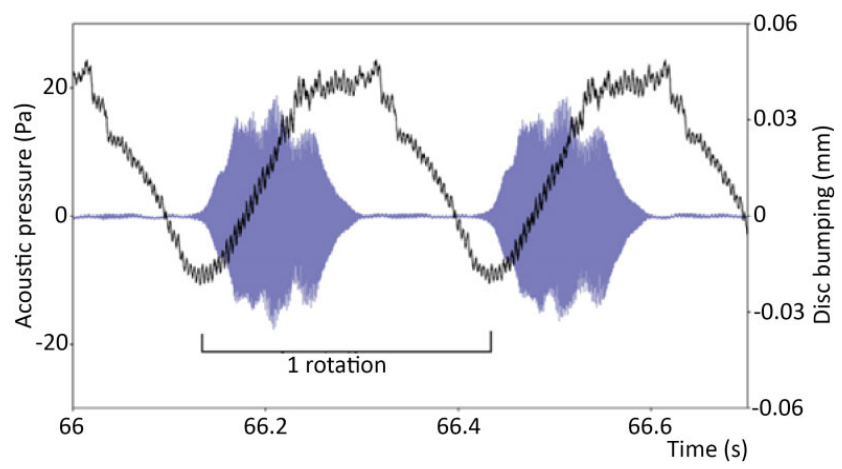

Fig. 15 Correlation between disc bumping and squeal. Reproduced with permission from Ref. [61], (c) Elsevier 2015. thickness of the disc was not uniform. They introduced a variation of the thickness as a function of the disc. The second geometric imperfection was the plateau as a function of the friction pad. The two geometric imperfections cause a variation in the noise generated due to the disc bumping as seen in Fig. 15.

A similar analysis regarding pad-on-discs systems was performed by Wang et al. [2]. Dynamic Transient Analysis using ABAQUS was performed as shown in Fig. 16.

The effect of groove-textured surfaces on the disc pad was investigated as shown in Fig. 17.

It was concluded that the geometry on the surface affected the noise generation. The sound pressure from the $90^{\circ}$ groove-textured surface was significantly lower than for the other surfaces. The $45^{\circ}$ and $135^{\circ}$ groove-textured surfaces had lower sound pressure than for the smooth surface and the 0 degrees groovetextured surface as seen in Fig. 18.

Jolivet et al. [62] studied the contribution of the differences in micro-geometry in gear tooth to the friction noise. To create those micro-geometries, two different finishing processes were applied to gear tooth while one was left unfinished. The surface of one gear tooth was powerhoned and the third one was grinded. The average amplitude of the noise spectrum

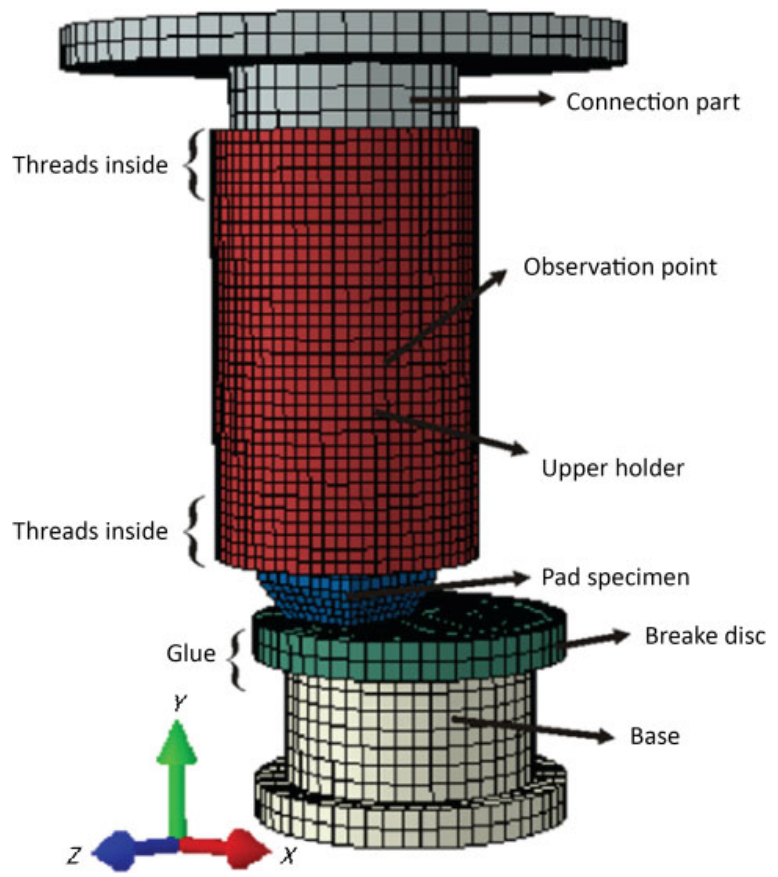

Fig. 16 FE model of the experimental system. Reproduced with permission from Ref. [2], (c) ASME 2016. 

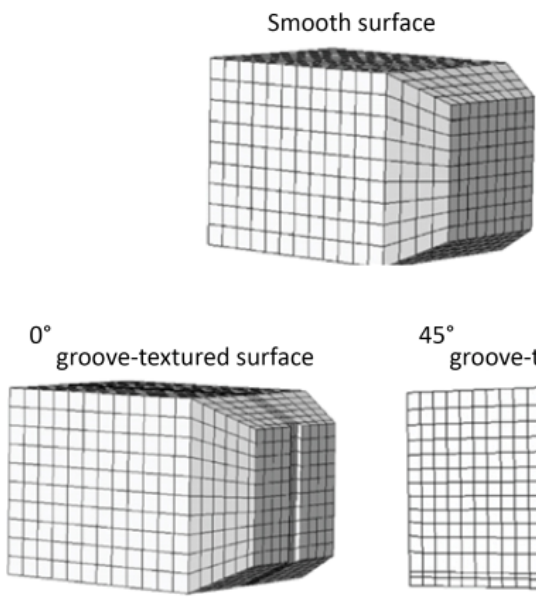

$45^{\circ}$

groove-textured surface
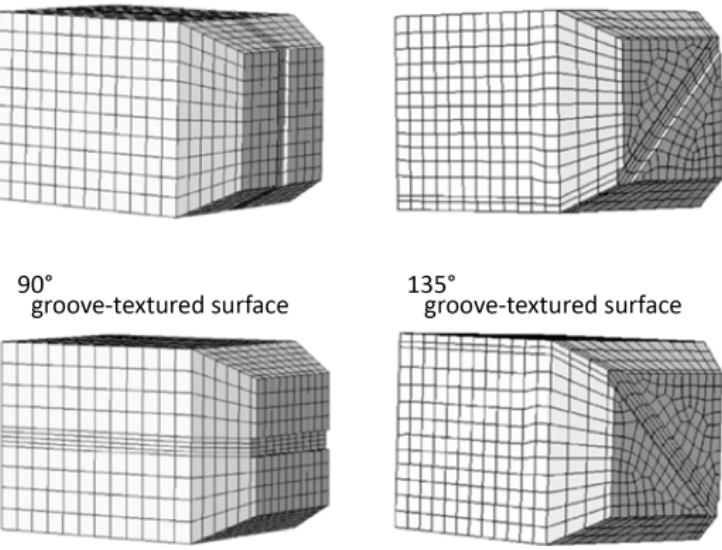

$135^{\circ}$

groove-textured surface

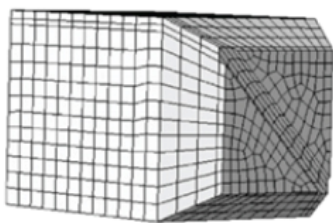

Fig. 17 Five kinds of the pad surfaces. Reproduced with permission from Ref. [2]. C ASME 2016.

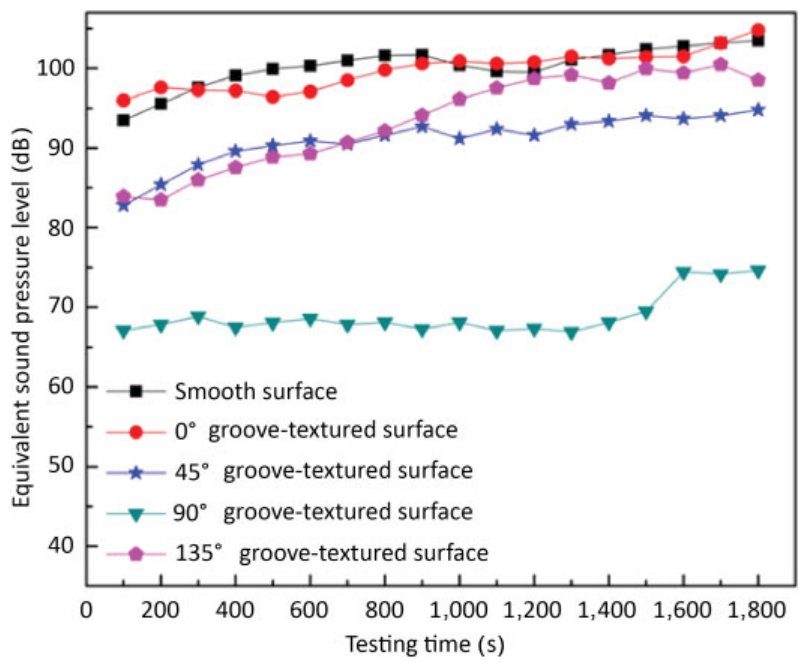

Fig. 18 Equivalent Sound pressure level for five surfaces. Reproduced with permission from Ref. [2], CASME 2016.

for the unfinished gear tooth was higher than for the other two finishing processes (which are close). This is shown in Fig. 19.

\section{Surface roughness and friction noise}

The accumulating wear debris will lead to a change in the surface roughness of the sample. To study the relationships between the surface roughness and
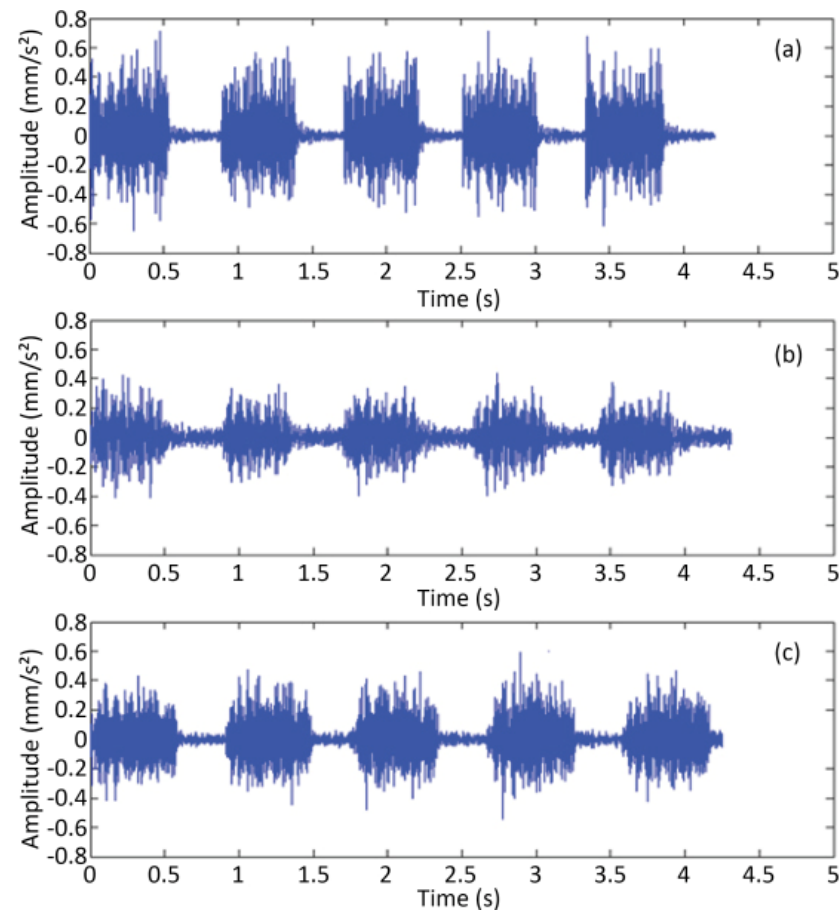

Fig. 19 Measured raw vibratory signal at $10 \mathrm{~mm} / \mathrm{s}$ for (a) not finished, (b) grinded, and (c) powerhoned tooth surfaces. Reproduced with permission from Ref. [62], (c) Elsevier 2017.

the friction noise, the most common experimental setups consist of pin-on-discs experiments as they are the simplest to use and give an accurate description of real-world mechanisms.

\section{Pin-on-disc based empirical research}

Yokoi and Nakai [63] studied experimentally the frictional noise generated by a clamped rod rotating on a steel disk. It was concluded that the noise was generated because the coefficient of friction between the rod and the disk was small and the sliding surface is rough. However, they found that as the sliding distance increased, the surface of the disk became smoother which greatly increased the coefficient of friction which altered the sound pressure levels (as shown in Fig. 20). The sound pressure levels would increase as the friction increased.

There have been other attempts to experimentally determine the relationship between the rubbing noise and the surface roughness. Othman and Elkholy [64] devised a device to measure the roughness of a surface based on the frictional noise generated. It consists of a steel blade which has a tungsten carbide tip. The blade is inclined at an angle from the surface to be 

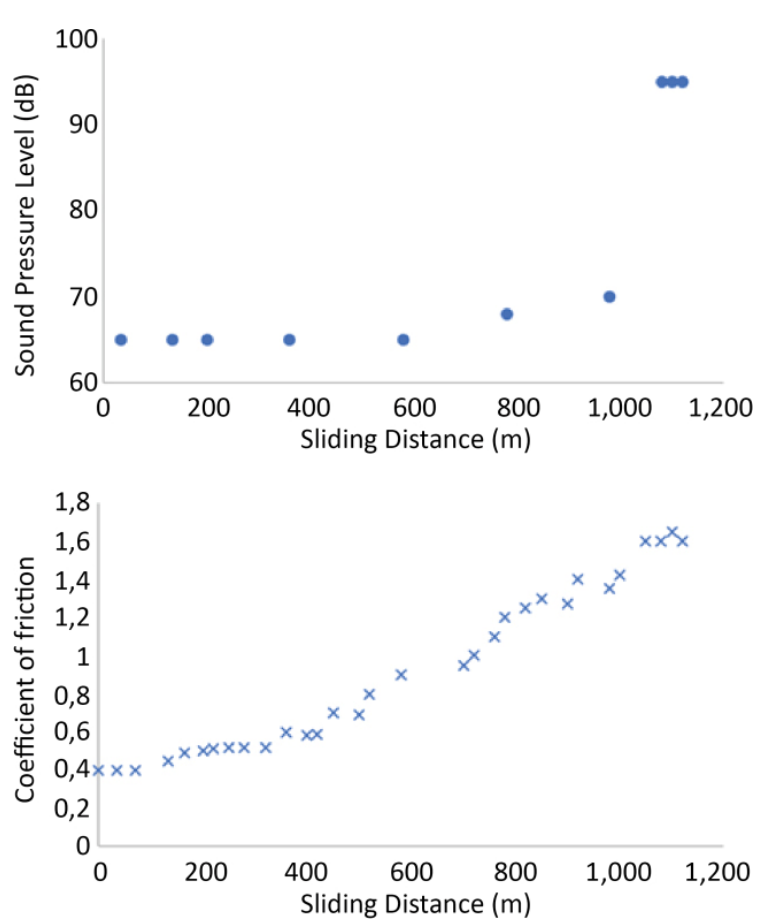

Fig. 20 Coefficient of friction and sound pressure level vs. sliding distance. Reproduced with permission from Ref. [63], (C) JSME 1979.

measured. The blade oscillates due to an electromagnetic exciter at a constant frequency inside a small anechoic chamber. The sound is detected by the microphone and the sound level is recorded by a sound meter.

The surface roughness could then be measured using the following equation:

$$
R=A(S P L)^{b}
$$

where $R=$ surface roughness, $S P L=$ sound pressure level, and $A$ and $b$ are experimental parameters.

The assumption made that if the frictional force is small enough to excite just the rod, then the generated frictional noise is proportional to the surface roughness. However, there are limitations to this assumption. If the frictional force increases and becomes too large, the whole system would be excited and the relationship between the frictional noise and the surface roughness would no longer be directly proportional.

Othman and Elkholy [65] also determined that regardless of surface roughness and contact load, the sound spectrum would always have a sharp peak (the dominant frequency) as shown in Fig. 21. The dominant frequency is dependent on the materials
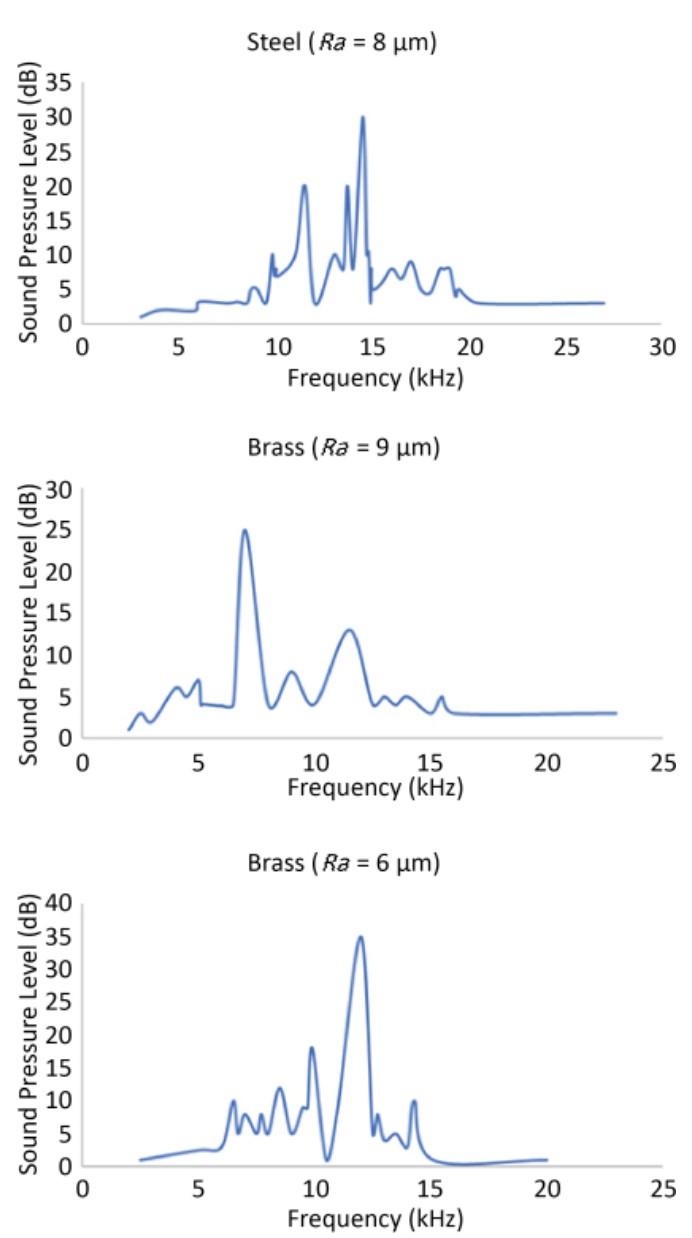

Fig. 21 SPL spectrum in frequency domain for different materials (contact load $=0.50 \mathrm{~N}$, all cases). Reproduced with permission from Ref. [65], (C) Springer 1990.

used in the pin-on-disc experiment. They also found that the magnitude of the dominant frequency is linearly proportional to the speed of sound in that material.

Yokoi and Nakai [66] also determined the influence of the surface roughness on the generation of noise on a pin-on-disc experiment. It was found that as the surface roughness increased, the sound pressure level also increased as shown in Fig. 22.

By considering the two different vibration modes of the pin, the acceleration of the pin was calculated, and they converted the acceleration of the pin to the sound pressure level. It was found that the largest peaks in the sound pressure level corresponded to the natural bending frequency of the pin.

Stoimenov et al. [67] studied the frictional noise produced during the dry sliding of two flat-flat surfaces. The largest change of the sound spectrum 


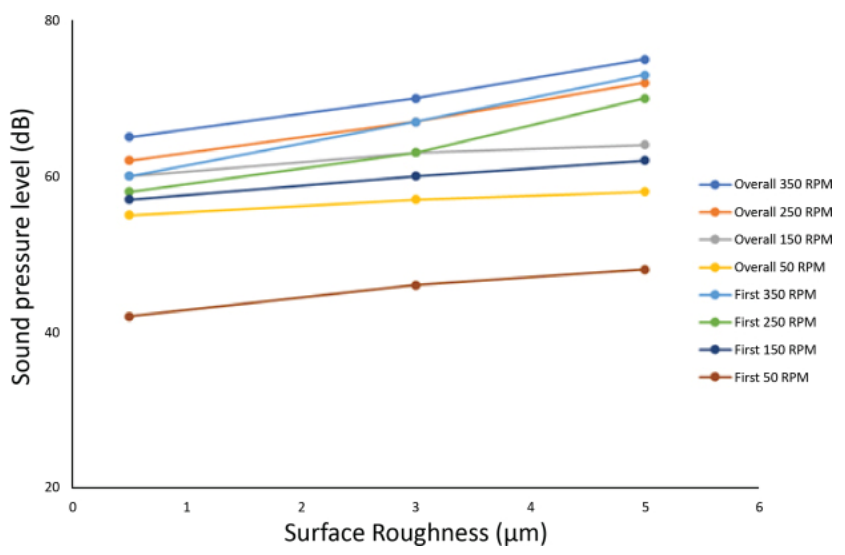

Fig. 22 Relation between sound pressure level and surface roughness for various revolutions of the disk ( $\operatorname{Rod} 3 \mathrm{~cm}$ in length). Reproduced with permission from Ref. [66], C JSME 1982.

peak due to the surface roughness was close to the fundamental natural bending frequency of the sample. This research therefore agrees with the previous pinon-disk research which arrived at a similar conclusion. However, the experiment was not performed under constant load or sliding speed which could lead to a decrease in accuracy of the results as the sensitivity of the constant load or the sliding speed on the frequency of the frictional noise was not determined.

\section{Simulation and modelling}

Rubbing noise was also studied numerically by Ben Abdelounis et al. [68]. They used ABAQUS 2D to simulate the roughness noise. The noise was generated by the impacts between the antagonist asperities across the surface which then converted the kinetic energy of the impact to a vibrational energy which was responsible for the radiation of sound. It was shown that the sound pressure level was a function dependant on the logarithm of the surface roughness and the sliding speed as shown in the following equation:

$$
\Delta L v(\mathrm{~d} B)=20 \log \left[\left(\frac{R_{a 2}}{R_{a 1}}\right)^{n} \cdot\left(\frac{V_{2}}{V_{1}}\right)^{m}\right]
$$

As the sliding speed and the surface roughness increase, the number of impacts per second decreases, but their intensity increases which leads to a higher intensity in the sound generated.

Earles and Lee [44] used modal analysis to analyse the behaviour of disc brake systems, most notably the generation of squeal noise. It was Jarvis and Mills [69] who first attempted to determine experimentally the generation of squeal noise. However, there were limitations with their model. For example, only one mode of vibration was considered. The system consisted of a pin supported in a way that it had two modes of oscillation. Those were one translational mode and one rotational mode. The model therefore had two degrees of freedom. However, it is possible to go even further. North created a ten-degrees-offreedom model to represent the vibration of disc brakes [70]. Through these models, it becomes possible to predict the mechanisms that cause brakes to squeal and thus actions can be taken to minimise the squeal in disc brakes through changes in design.

Simo and Laursen [71] created numerical models involving contacts using the Augmented Lagrangian formulation. This is a penalty-based formulation in which the contact force is a function of contact stiffness. The higher the contact stiffness, the lower the penetration is. The Augmented Lagrangian formulation was also used by Hirmand et al. [72]. It is also a non-linear model in which the Coulomb friction rule was implemented to simulate the stick-slip behaviour on the contact interface.

One of the major drawbacks of the numerical implementation of the Coulomb friction is the fact that the law is non-associative. This results in a non-symmetric mapping. However, most solvers are symmetric solvers such as Gaussian eliminations. Non-symmetric solvers do exist, but they are very computationally expensive. Laursen and Simo [73] worked on an adapted algorithm that would create a symmetrical Coulomb frictional problem that could then be applied to the Augmented Lagrangian formulation.

Oden and Martins [74] created numerical models for the stick-slip phenomena. Their models could be used to predict stick-slip, sliding resistance, and frictional damping. They divided the mechanisms of friction into two different categories. Type 1 friction was classified as quasi-static dry friction which has been investigated by other researchers prior. Type 2 friction was classified as dynamic sliding friction which includes stick-slip friction. However, their models had a few limitations as they did not account for the change 
in the coefficient of friction with velocity, nor did they consider the difference between the static and the dynamic coefficients of friction. However, it has been known for a long time that the coefficient of friction decreases as the sliding velocity increases [75].

Slavič et al. [76] devised a numerical model using Poisson impacts and the Coulomb laws of friction between random rough surfaces to investigate their effects on the roughness-induced vibrations. They also included the wear model and investigated the effects that the wear would have on the frequency and amplitudes of the vibrations. The inclusion of wear would affect the dynamics of the system as the contact points would change and it would force other contacts to support the load. To devise their model, they started with a model consisting of one degree of freedom and one contact point. They later expanded their model to include two contact points and extended it again to include multiple contact points and thus simulate the whole system.

Another model was developed by Kang [77]. The model was focused on the stick-slip oscillation of disc brake systems and a time-transient analysis was performed. The main difference between this model and the model developed by Jarvis and Mills is that this model uses non-linearized equations of motions whereas the one by Jarvis and Mills [69] used the linear equations of motions. This model is therefore more comprehensive than other models because linear models fail to account for the squeal generation far from the steady-state equilibrium.

As can be seen, the sound generated due to the friction process change is highly dependent on the response of the system that the friction force interacts with. This interaction sets up a feedback between the friction force and the sound waves generated. Those dynamic effects have short time scales. However, there are other components with much longer time scales that will alter the friction and the sound generated. The wear of surfaces will have a major impact on the response of the system. Therefore, a simple linear system can still produce complicated responses as the time scale increases due to the deformation and the wear of the surfaces [12].

The models presented in this section shows a clear dependence between the wear and the friction noise as well as the friction coefficients. As wear starts to develop on the surfaces during sliding friction, the coefficient of friction greatly increases as the surface roughness of the surface is altered. This leads to an increase in the sound generated. There is also a dominant frequency in the sound spectrum irrespective of the sliding speed or the surface roughness. This dominant frequency is dependent on the material used. However, there are still gaps that need to be addressed. Most models presented are empirical. The numerical models use Coulomb's laws of friction as a basis. The analytical models presented in this section which establish the interdependence of friction coefficients and friction induced vibrations do not include an analytical expression for the wear calculations. As such, an analytical model that combines all three principal components of the friction processes has not yet been established.

\section{Acoustic performance and noise due to wear}

There are two distinct categories of noise generated during friction and wear processes. The acoustic noise and the airborne noise. This section details the process behind the airborne and the acoustic noise generated during the friction process. This section then describes the relationship between the acoustic/ airborne noise and the wear that occurs during the friction process.

\section{Friction or airborne noise and wear}

During the friction processes, energy is transferred due to the work done on the asperities. There are two types of deformation that can occur as a result. The asperities can either undergo plastic or elastic deformation. During elastic deformation, the energy is converted to noise. During plastic deformation, there is no noise component. However, the wear will contribute to the noise as the wear debris accumulate between the two surfaces as they create additional bodies that will impact the asperities and the impact energy will be converted to noise. This was also determined experimentally. Stoimenov and Kato [78] determined that wear had an impact on the generation of sound. In their experimental setup, adhesive wear occurred which caused a build-up of material on the 
surface of the disc. Those lumps of material (which were therefore higher than the original surface asperities) caused spikes in the sound spectrum that were correlated with the frequency at which the materials were attaching to the surface asperities during the sliding process. This research showed that friction generated a noise spectrum which was subsequently altered as wear occurred during the sliding process. The distance between subsequent spikes in the power spectrum were correlated with the distance between each lump of material. This is shown in Fig. 23.

Wang et al. [79] investigated the effect of surface roughness on the generation of squeal on a ballon-flat surface. The ball was made of ceramic while the flat surface was made of graphite iron. All samples were polished and sandblasted to obtain a random surface roughness distribution. The smooth surface led to a higher sound pressure than the sandblasted surfaces. Squeal occurred due to the accumulating wear particles, ploughing, adhesion, and detachment which is consistent with the previous research mentioned. However, the surface roughness had a major impact on the generation of squeal. The sandblasting of the surfaces caused a larger spread between asperities. Due to the larger distance between asperities in the sandblasted surfaces, the major mechanism of wear in those surfaces was due to ploughing. This possesses weak energy and thus leads to a lower sound spectrum. This confirms that wear debris and adhesion is a larger contributor to the high-frequency sound generation, which is what ultimately leads to squeal noise.

Since friction noise is closely related to wear, reducing wear would also reduce the friction noise. As such, Chen et al. [80] investigated how adding Titanium Silicocarbide to matrix composites would reduce the wear and by extension, the friction noise. Different proportions of Titanium silicocarbide were added to the matrix composite. The samples tested included MT0 (no titanium silicocarbide added), MT5 (5\% added), MT10 (10\% added), and MT15 (15\% added). The results are shown in Fig. 24.

The sound pressure of MT0 is the highest. The main mechanism of wear in that sample is adhesive wear (electron microscopy shows the presence of wear debris on the surface). This therefore agrees with the previous research that adhesive wear is the largest contributor to friction noise. In MT5, the main mechanism of wear is abrasive wear. The surfaces still produce wear debris, but unlike in the first case, they do not immediately detach from the surface, but are instead compacted due to the role of cyclic stress. Because of this, they gradually repair the worn surfaces

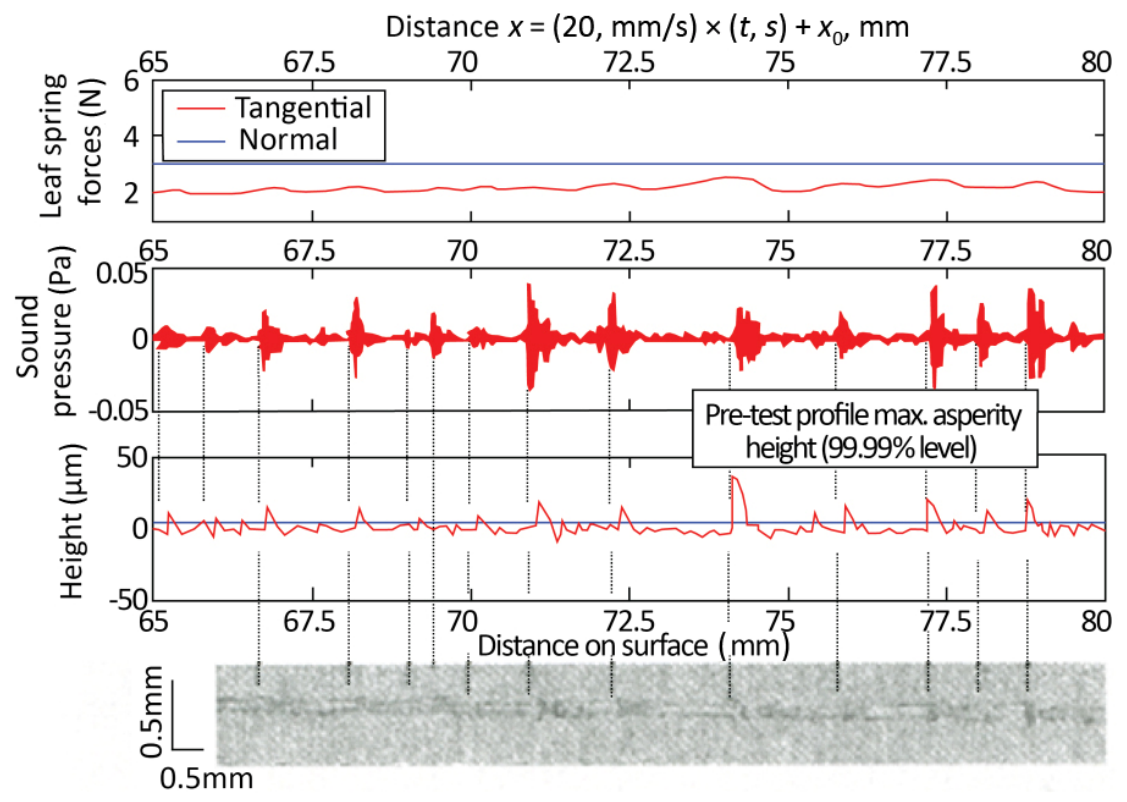

Fig. 23 Zoomed-up portion of sound pressure signal at $3.0 \mathrm{~N}$ together with wear scar profile, scar photograph, and strain-gauge measured elastic forces. Reproduced with permission from Ref. [78], (C) Elsevier 2003. 

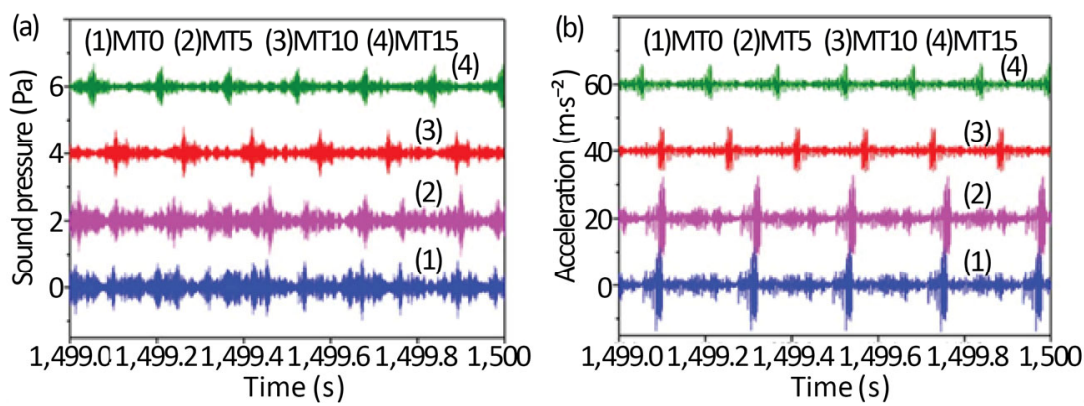

Fig. 24 (a) Sound pressure and (b) vibration acceleration of MT0, MT5, MT10, and MT15 at 1,500 s. Reproduced with permission from Ref. [80], ( IOP Publishing Ltd 2019.

and as such, reduce the wear and the friction noise. MT10 was found by EDS analysis that there were many oxygen molecules present on the surface of the sample. This led to the conclusion that in this sample, the main wear mechanism was oxidation wear which does not contribute to the friction noise. Hence MT10 shows the least amount of noise. However, in MT15, adhesive wear becomes a factor again and so the noise level of MT15 is higher than for MT10.

The change in surface roughness also changes the sound pressure levels. This was shown by previous researchers [81]. However, an in-depth study of wear debris and contamination of the surfaces was also necessary. This would correlate the friction noise to the wear volume generated. Most of the research correlating wear with the coefficient of friction and friction noise has been experimental [82]. Nam et al. [83] studied experimentally the effect of lubricated contacts on friction noise. They compared two scenarios: One in which the lubricant was applied on the clean surface, and the second one where lubricant was applied on a surface contaminated by wear debris. Lubrication is used to mitigate friction and friction noise. However, as time progresses, the amount of lubricant between the two surfaces decreases. This leads to an increase in the friction coefficient and thus leads to an increase in friction noise as shown in Fig. 25.

However, for the contaminated surface, there was no increase in friction coefficient despite an increase in noise (Fig. 26). This shows that wear does have an impact on friction noise.

Another research correlating wear and friction was performed by Mo et al. [84]. The experimental study was done on groove-textured surfaces. It was found that there was no correlation between the noise generated and the coefficient of friction which agrees with other research [85]. The noise was mainly generated due to the wear debris accumulating on the worn surfaces thus changing the topography of the surface. Groove-textured surfaces also generate less noise than smooth-surfaces as it allows the wear debris an easier escape from the contact points.

Chen et al. [86] categorised four different phases of squeal generation under wear. In the first stage, no squeal is emitted. In the second stage, squeal is not
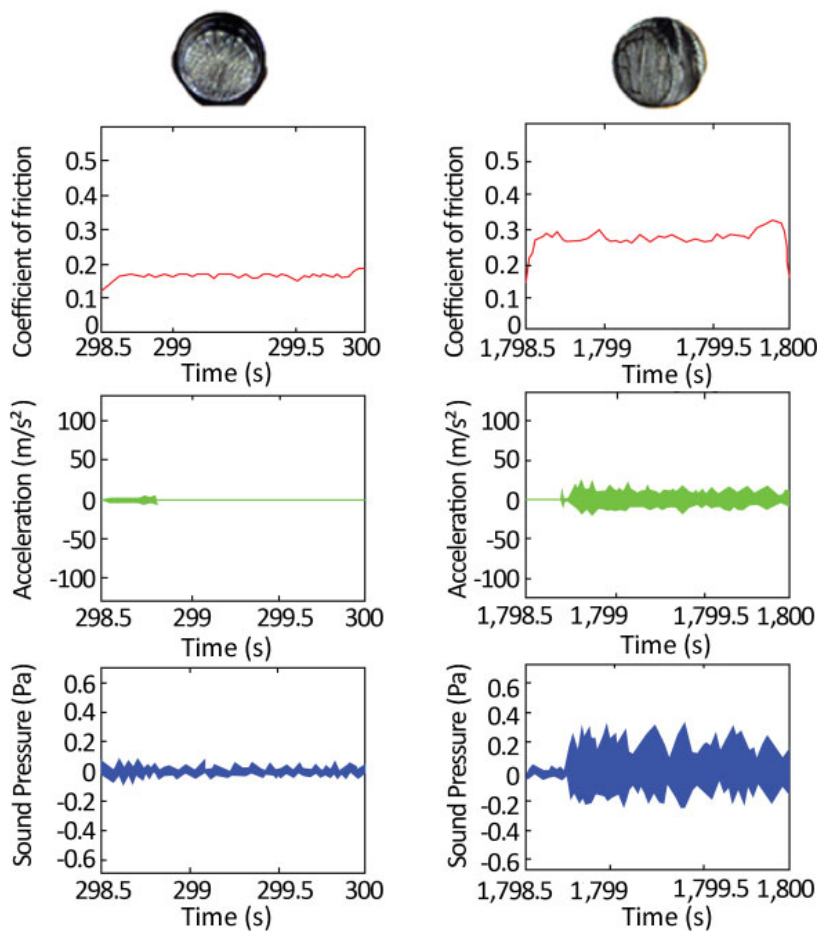

Fig. 25 Surface topology and time history of friction coefficient (top), vibration (middle), and sound pressure (bottom) for lubrication on the clean surface in the reciprocating test after (a) $298.5 \mathrm{~s}$ and (b) $1798.5 \mathrm{~s}$. Reproduced with permission from Ref. [83], C Springer 2017. 

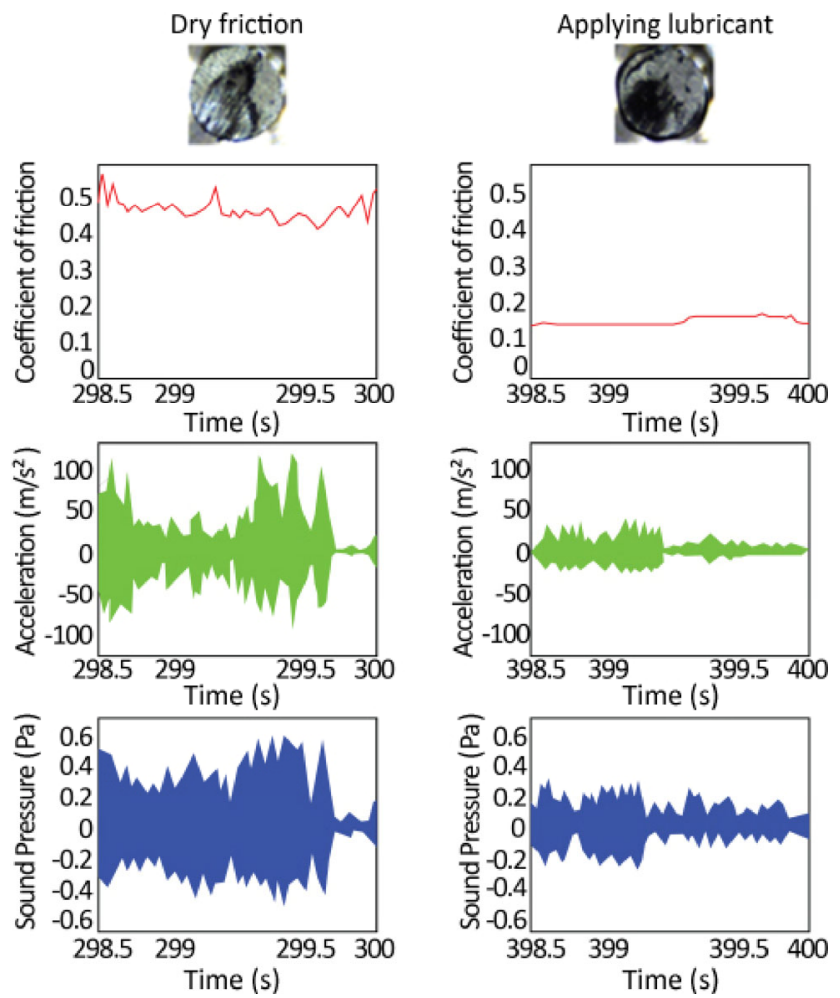

Fig. 26 Surface topology and time history of friction coefficient (top), vibration (middle) and sound pressure (bottom) for the contaminated lubrication by wear debris in the reciprocating test after (a) $298.5 \mathrm{~s}$ and (b) $598.5 \mathrm{~s}$. Reproduced with permission from Ref. [83], (C) Springer 2017.

emitted as the coefficient of friction is too small. In the third stage as the coefficient of friction increases, squeal is emitted. On the final stage, the squeal disappears.

Several other researchers studied how temperature affected the wear rate [87-90]. For low temperatures, the wear rate was mostly constant. However, as the temperatures exceed a certain value, commonly 500 degrees Celsius, then the wear rate increases exponentially with increasing temperature (as shown in Fig. 27).

The role of wear in friction noise was also investigated by Duarte et al. [91]. They focused on the role of wear debris accumulating between the surfaces and developed a power spectrum model for the friction force. The presence of loose debris has a strong impact on the friction force and the generation of friction noise. The experiment was carried out using an aluminium pin sliding on a steel disc. Two sets of experiments were performed. The first set was performed without the presence of debris whereas the second set was performed with wear debris blowing and accumulating between the surfaces as shown in Fig. 28.

Jibiki et al. [92] studied the friction noise that was caused by fretting. They used a crossed-cylinder configuration comprised of carbon steel and mild steel and calculated the friction force, as well as the noise that was generated during fretting. The fretting cycle consists of two phases: tension and compression. Friction noise only occurs during the tension phase, but never during the compression phase as shown in Fig. 29.

Their model allowed to experimentally correlate the amount of wear and the friction noise. Several other studies examined how the accumulating wear debris would change the contact conditions $[93,94]$.

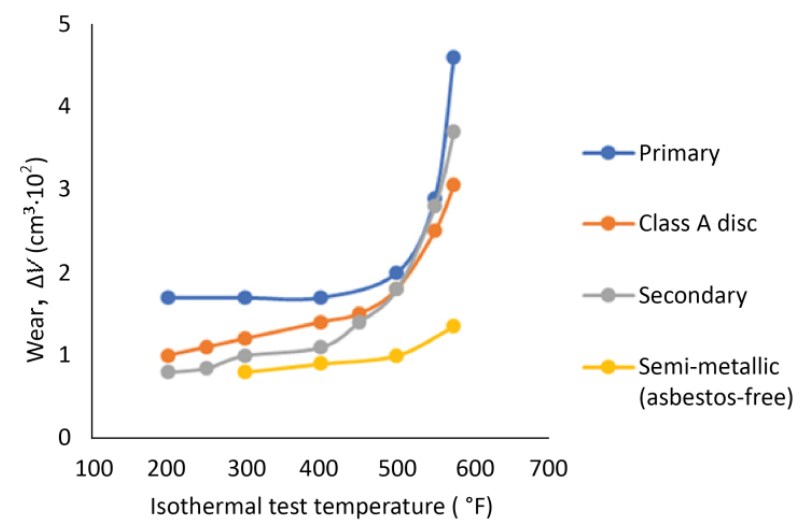

Fig. 27 Variation in frictional wear with temperature. Reproduced with permission from Ref. [90], (c) Elsevier 1974.

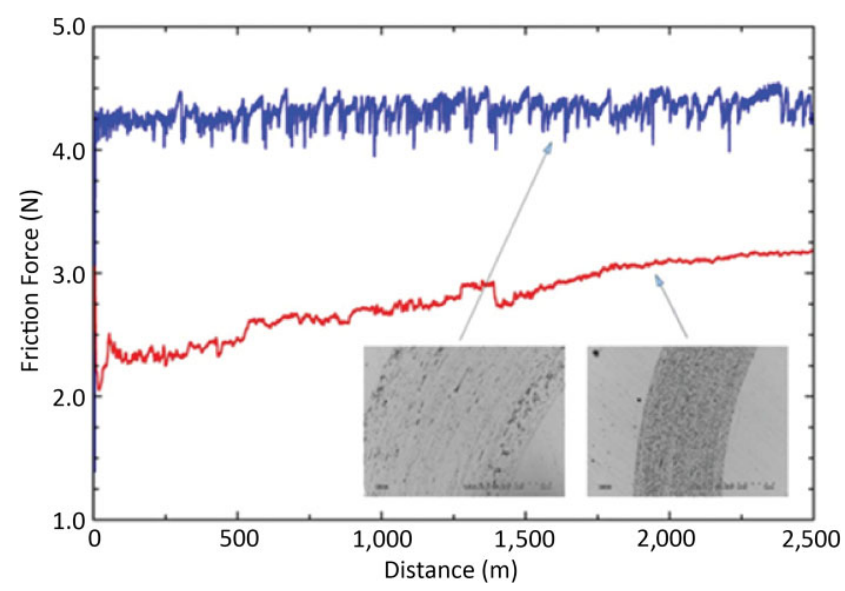

Fig. 28 Running averages of the friction force vs. time derived from experiments carried out on SAE 52100 steel with an alumina pin at a load of $5 \mathrm{~N}$ and a sliding speed of $10 \mathrm{~cm} / \mathrm{s}$. Data were taken at $20 \mathrm{~Hz}$ and averages were done over successive ranges of $50 \mathrm{~s}$. Reproduced with permission from Ref. [90], (C) Elsevier 1974. 


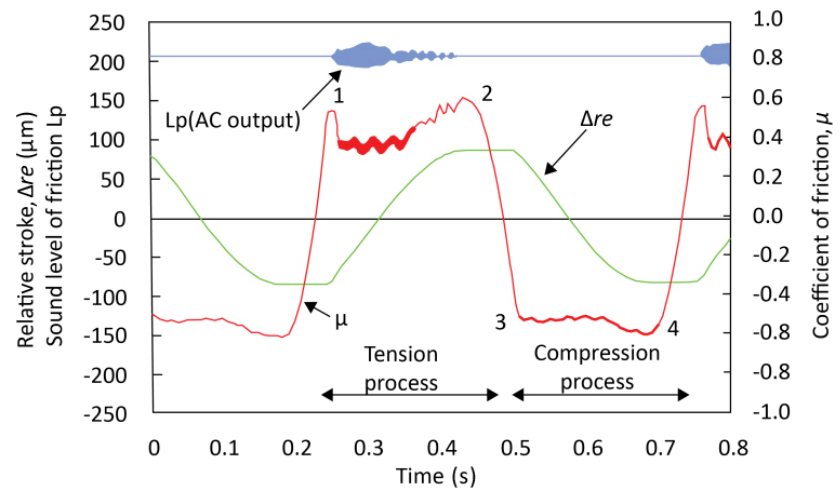

Fig. 29 Typical example showing waveforms of friction noise (AC output), coefficient of friction, and relative stroke. Reproduced with permission from Ref. [92], (C) Elsevier 2001.

In summary, it was shown that the airborne noise was correlated to wear during the friction processes. For example, as wear increases, and the amount of wear debris accumulates, this leads to an increase in friction noise due to the wear debris. Temperatures also have an indirect impact on the friction noise. Higher temperatures directly increase the wear rate, and this leads to an increase in the friction noise. However, the coefficient of friction does not impact the generation of airborne noise. All the research presented in this section were experimental. A potential direction for future research could be to implement an analytical model of heat generation along with the friction and wear models. It would then be possible to apply it under a wider range of conditions.

\section{Effect of acoustic performance on the friction process}

Acoustic emissions are transient elastic stress waves generated at the source by the rapid release of strain energy within a material. These radiating stress waves are detected at the surface of the body by a suitable transducer. Those can occur due to different phenomena such as asperity contact, micro-crack initiation and growth and plastic deformation. Those are the same phenomena that are linked to friction and wear. As such, it is possible to link wear to acoustic performance the same way it was linked to the noise. Boness and McBride [95] studied the acoustic emission produced under different wear conditions. This is shown in Fig. 30.

As can be seen from Fig. 30, adhesive wear leads to a massive acoustic signal. During abrasive wear, the signal is a lot lower. This correlates with other research which suggests that adhesive wear is also what produces the higher noise as opposed to other wear mechanisms. It was also shown that adding third-body abrasive particles also reduces the acoustic emission produced as shown in Fig. 31.

The RMS signal also increases a lot for the test without abrasive particles as opposed to the test with abrasive particles. Boness et al. [96] also studied how the acoustic emission varied between lubricated and unlubricated contacts. This is shown in Fig. 32.

The RMS signal is much higher for unlubricated contacts than it is for lubricated contacts. This is also in correlation with the noise generation. Dry contacts lead to a higher noise generation than lubricated contacts. The wear is also much higher, as shown in Fig. 33.

This agrees with other research that link an increase in wear to an increase in noise. Thus, an increase in acoustic emission will also lead to an increase in noise. Benabdallah and Aguilar [97] investigated the relationship between the acoustic emission and the

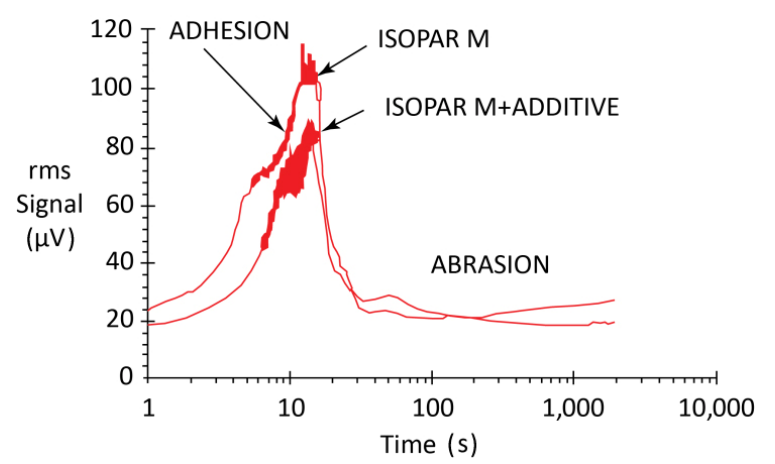

Fig. 30 RMS signal vs. time. Reproduced with permission from Ref. [95], (C) Elsevier 1991.

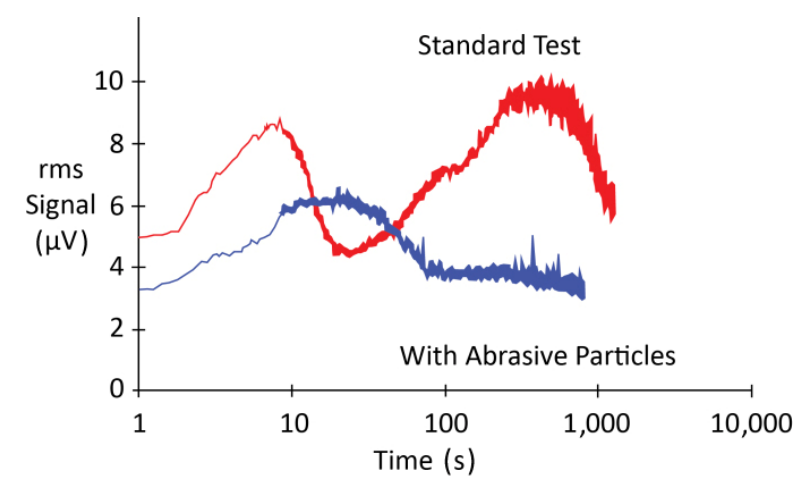

Fig. 31 RMS signal vs. time. Reproduced with permission from Ref. [95], (C) Elsevier 1991. 


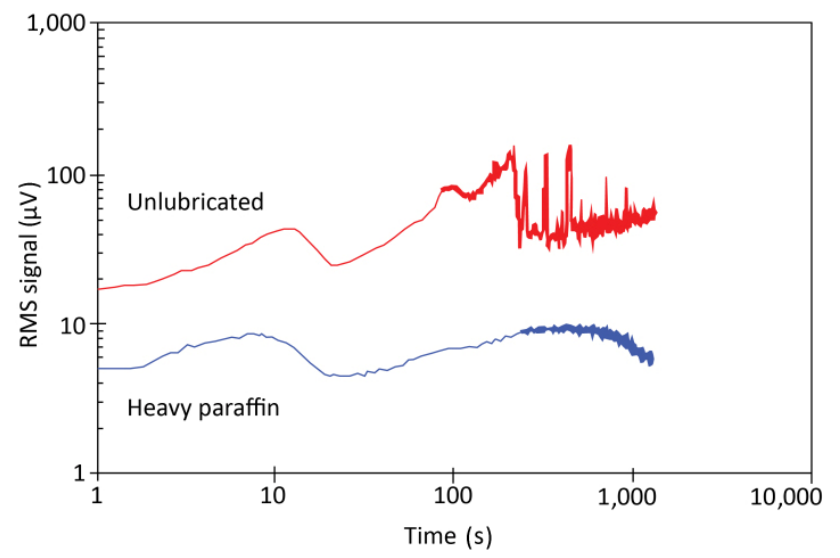

Fig. 32 Acoustic emission - RMS vs. time. Reproduced with permission from Ref. [96], (C) Elsevier 1990.

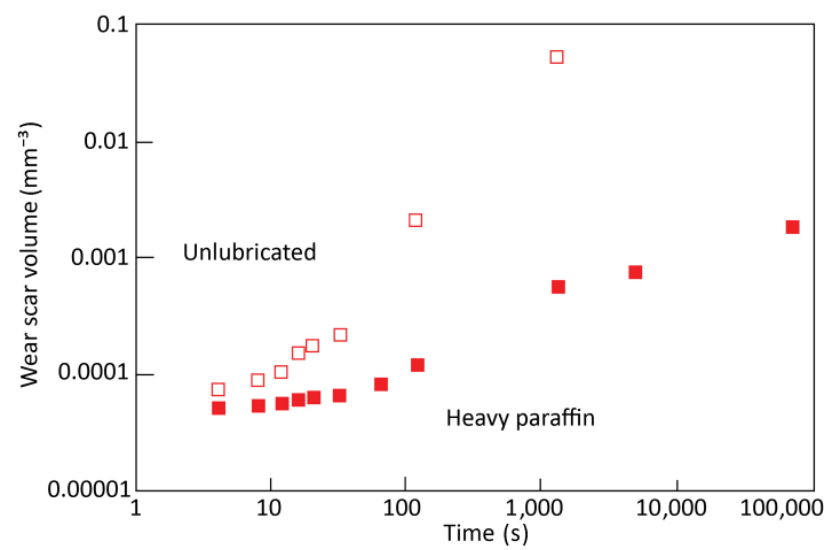

Fig. 33 Wear scar volume vs. time. Reproduced with permission from Ref. [96], (C) Elsevier 1990.

friction and wear of the surfaces. This is shown in Fig. 34.

As the coefficient of friction increases, so too does the acoustic emission. The relationship between the

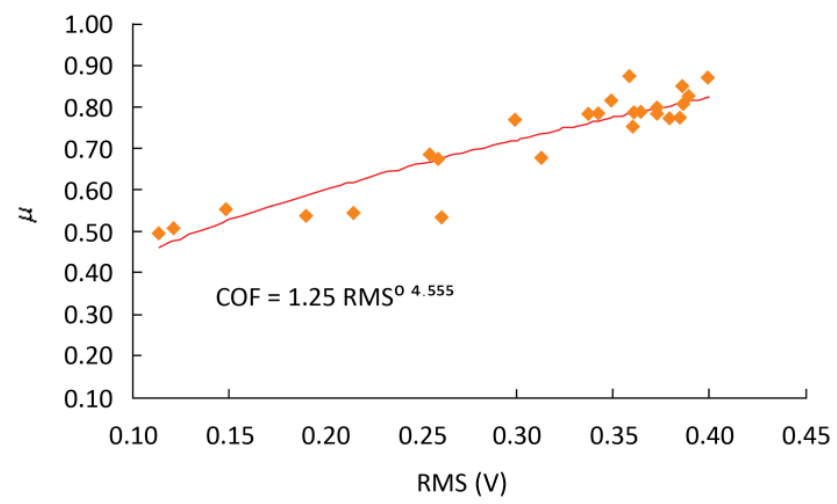

Fig. 34 Relationship between COF and AE RMS voltage. Reproduced with permission from Ref. [97], C Informa UK Limited 2008. frictional work and the wear rate are shown in Figs. 35 and 36 .

The conclusion that can be drawn from the research into the impact of friction and wear on acoustic processes is that the acoustic emissions increase as the wear rate increases. The acoustic emissions are also impacted by the coefficient of friction as they increase as the coefficient of friction increases. This is different to the generation of airborne noise seen in the previous section.

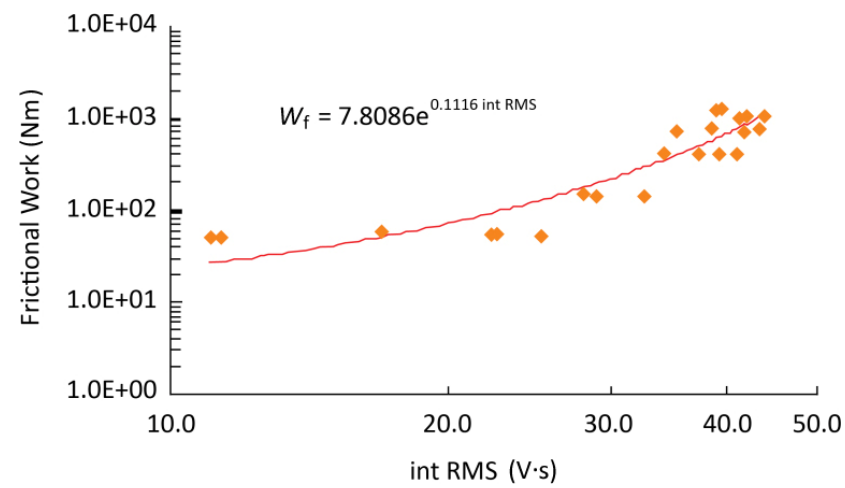

Fig. 35 Frictional Work as a function of IntRMS. Reproduced with permission from Ref. [97], (C) Informa UK Limited 2008.

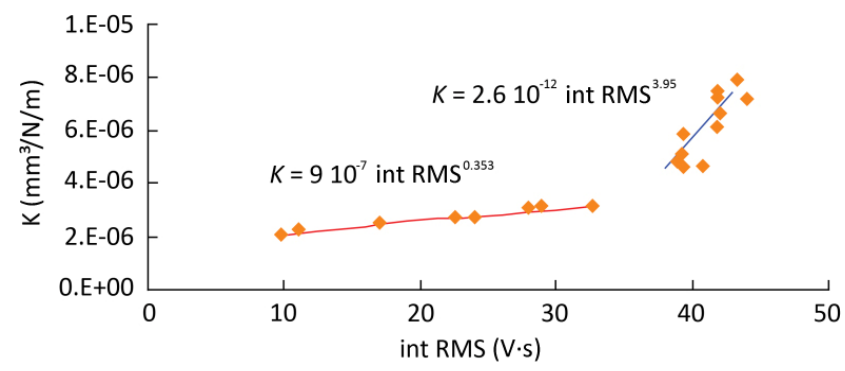

Fig. 36 Wear rate as a function of Int RMS. Reproduced with permission from Ref. [97], (C) Informa UK Limited 2008. Where int $\mathrm{RMS}=\int R M S \mathrm{~d} t$. Both the wear rate and the frictional work increase with respect to the acoustic emission. It is worth noting that there are two distinct regions for the wear rate. It was found that the difference occurs when the sliding speed increases past $0.18 \mathrm{~m} / \mathrm{s}$.

\section{Modelling friction and wear}

\section{Wear models}

There has been extensive research on different wear models. Meng et al. [98] and Yadav et al. [99] provided a comprehensive review on the different wear models 
in the literature and their origins. It was found that there are no general equations for wear. There are substantial varying parameters with different meanings. This is because wear is dependent on a lot of different factors and not all of them are understood. Barwell [100] described the process of wear formation and the mechanisms of wear in different practical applications. The four examples chosen to illustrate the mechanisms of wear were scuffing, rolling contacts, fretting corrosion, and simple sliding. Their effects on industrial machineries can be seen in engine cylinders, engine bearings, or gears. There are a lot of factors due to the wide variations of material properties and rubbing surfaces that determine how wear will proceed and whether it will lead to machine failure and there are still vast amounts of ongoing research in the industry [101]. Some of the wear model used are described in Table 1.

Table 1 Common wear models.

\begin{tabular}{|c|c|c|c|c|}
\hline Model type & Author (year) & Wear type & Advantages & Limitations \\
\hline $\begin{array}{l}\text { Numerical } \\
\text { model }\end{array}$ & $\begin{array}{l}\text { Shen et al. } \\
(2010)[102]\end{array}$ & $\begin{array}{l}\text { Sliding } \\
\text { wear }\end{array}$ & $\begin{array}{l}\text { Input parameters easily calculated through } \\
\text { ABAQUS }\end{array}$ & $\begin{array}{l}\text { Based on Archard Wear model and is } \\
\text { only empirical. Precision is limited by } \\
\text { mesh quality. Computationally expensive } \\
\text { with fine meshes }\end{array}$ \\
\hline $\begin{array}{l}\text { Numerical } \\
\text { model }\end{array}$ & $\begin{array}{l}\text { Hassan and } \\
\text { Mohammed } \\
(2016)[103]\end{array}$ & $\begin{array}{l}\text { Sliding } \\
\text { wear }\end{array}$ & $\begin{array}{l}\text { Artificial Neural Networks provides high } \\
\text { accuracy in modelling the sliding wear } \\
\text { processes }\end{array}$ & $\begin{array}{l}\text { Artificial Neural Networks requires a } \\
\text { lot of data for training and validation } \\
\text { purposes. Skewed data or data containing } \\
\text { errors can cause the ANN to be trained } \\
\text { in the wrong direction causing invalid } \\
\text { outputs }\end{array}$ \\
\hline $\begin{array}{l}\text { Empirical } \\
\text { model }\end{array}$ & $\begin{array}{c}\text { Rhee }(1970) \\
{[104]}\end{array}$ & $\begin{array}{l}\text { Sliding } \\
\text { wear }\end{array}$ & $\begin{array}{l}\text { Providing the correct input parameters are } \\
\text { used, the correlation is good }\end{array}$ & $\begin{array}{l}\text { Restricted applicability. Furthermore, } \\
\text { input parameters are highly dependent } \\
\text { on the test conditions and can be hard } \\
\text { to establish }\end{array}$ \\
\hline $\begin{array}{l}\text { Empirical } \\
\text { model }\end{array}$ & $\begin{array}{l}\text { Archard and } \\
\text { Hirst (1956) } \\
\quad[105]\end{array}$ & $\begin{array}{l}\text { Sliding } \\
\text { wear }\end{array}$ & $\begin{array}{l}\text { The experimental results correlate well with } \\
\text { this model once the equilibrium position is } \\
\text { reached. This model is also simple }\end{array}$ & Only works in unlubricated conditions \\
\hline $\begin{array}{l}\text { Theoretical } \\
\text { model }\end{array}$ & $\begin{array}{c}\text { Archard } \\
(1959)[106]\end{array}$ & $\begin{array}{l}\text { Sliding } \\
\text { wear }\end{array}$ & $\begin{array}{l}\text { This model presents a simple approach to } \\
\text { determining the flash temperatures at the } \\
\text { contact interface during the wear processes }\end{array}$ & $\begin{array}{l}\text { The ideal situations presented in the } \\
\text { model may not be accurate depending } \\
\text { on the actual test conditions }\end{array}$ \\
\hline $\begin{array}{l}\text { Theoretical } \\
\text { model }\end{array}$ & $\begin{array}{l}\text { da Silva and } \\
\text { Pintaude } \\
(2008)[107]\end{array}$ & $\begin{array}{l}\text { Sliding } \\
\text { wear }\end{array}$ & $\begin{array}{l}\text { The Archard model was modified by intro- } \\
\text { ducing an uncertainty on the wear coefficient. } \\
\text { The worn height was treated as a stochastic } \\
\text { process which presented better results }\end{array}$ & $\begin{array}{l}\text { This model does not consider the } \\
\text { roughness coefficient }\end{array}$ \\
\hline $\begin{array}{l}\text { Empirical } \\
\text { model }\end{array}$ & $\begin{array}{l}\text { Quinn }(1971) \\
\quad[108]\end{array}$ & $\begin{array}{l}\text { Oxidational } \\
\text { Wear }\end{array}$ & $\begin{array}{l}\text { This model presents good results for the wear } \\
\text { of metals in unlubricated conditions }\end{array}$ & $\begin{array}{l}\text { The model only works for mild wear in } \\
\text { unlubricated conditions and only if the } \\
\text { appropriate input parameters are used }\end{array}$ \\
\hline $\begin{array}{l}\text { Numerical } \\
\text { model }\end{array}$ & $\begin{array}{c}\text { Öqvist } \\
\text { (2001) [109] }\end{array}$ & $\begin{array}{l}\text { Sliding } \\
\text { wear }\end{array}$ & $\begin{array}{l}\text { The model is fast and provides accurate } \\
\text { results at each time step }\end{array}$ & $\begin{array}{l}\text { The model only works on a macroscopic } \\
\text { scale and cannot determine how the } \\
\text { wear occurs on the molecular scale }\end{array}$ \\
\hline $\begin{array}{l}\text { Numerical } \\
\text { model }\end{array}$ & $\begin{array}{l}\text { Mukras et al. } \\
(2009)[110]\end{array}$ & $\begin{array}{l}\text { Sliding } \\
\text { wear }\end{array}$ & $\begin{array}{l}\text { The parallel implementation of the intermediate } \\
\text { cycle-update procedure where the geometry } \\
\text { is not updated at every step but at the end of } \\
\text { a cycle with a predetermined number of } \\
\text { steps drastically reduces computational time } \\
\text { while still providing reasonable accuracy }\end{array}$ & $\begin{array}{l}\text { In the absence of parallel computing } \\
\text { resources, the intermediate cycle-update } \\
\text { procedure loses its advantage. Other } \\
\text { implementations such as the step-update } \\
\text { procedure (where the geometry is updated } \\
\text { after each step) are also computationally } \\
\text { expensive }\end{array}$ \\
\hline $\begin{array}{l}\text { Empirical } \\
\text { model }\end{array}$ & $\begin{array}{l}\text { Savio et al. } \\
(2009)[111]\end{array}$ & $\begin{array}{l}\text { Sliding } \\
\text { wear }\end{array}$ & $\begin{array}{l}\text { The model shows a satisfactory estimate of } \\
\text { the surface roughness evolution during the } \\
\text { polishing process }\end{array}$ & $\begin{array}{l}\text { The model has limited applicability. } \\
\text { Furthermore, it cannot explain the } \\
\text { microscopic interactions occurring during } \\
\text { the wear processes }\end{array}$ \\
\hline
\end{tabular}


The main limitation of the wear models previously mentioned is that they are not analytical models, and they are suitable only for a specific set of applications. Fillot et al. [112] devised a general analytical model for a predictive wear equation. This analytical model introduces the third-body concept which places importance on the particles that have been detached during the wear process. The third-body concept includes the flow of those particles inside the contacts in the wear equations. With a third-body concept, the mechanisms of wear become a lot more different. For example, the third body will support the load, affect the velocity, and prevent the two surfaces from direct contact. This, in turn, acts as a layer of protection reducing the degradation of the surfaces. A diagram showing the third-body concept is shown in Fig. 37.

\section{Friction models}

Most of the research previously mentioned used the Coulomb's model of friction. However, there are several other existing models. Some of them are extensions and refinements of Coulomb's model. Friction models can be categorized in two different categories. There are empirical models (such as Coulomb's model) and physics-based models.

\section{Empirical models}

General friction models were developed as alternatives to the Coulomb friction model. This is because the Coulomb model of friction greatly oversimplifies the frictional phenomena. It is widely used in the engineering world, where dynamic effects are not concerned. Furthermore, the Coulomb model of friction is also a common piece of the more advanced models that are available. The main problem with the Coulomb

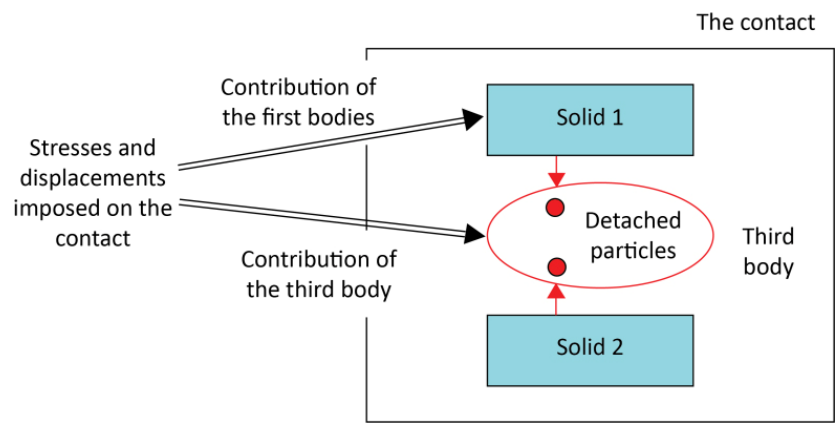

Fig. 37 Contribution of the third body to the stresses and displacements imposed to the contact. model is that it cannot handle the environment of zero velocity, hence the properties of motion at starting or zero velocity crossing, which are static and rising static friction. More advanced models based on the Coulomb model include the viscous friction model (where the friction force is proportional to the sliding velocity), or the Stribeck model (which still models the friction force as a function of velocity but includes both the standard Coulomb's model and the viscous model). However, it is still valid only for steady-state problems.

To simulate more complex problems, additional features become necessary. Those additional features will then allow to model dynamic behaviours. Unfortunately, the science of tribology is still far from understood [113] and so, most of those models are based on empirical evidence rather than deep scientific knowledge [114]. More complex models can be divided into two categories. The first category includes steady state models, and the second category includes dynamic models. Two common steady-state models are summarised in Table 2.

Unfortunately, there are a lot of disadvantages with using a static friction model. The main problem is detecting when the velocity is zero. Furthermore, the solutions to the equations of motions are nonunique [115]. Finally, numerical problems occur if static models are used to simulate forward dynamics problems. A dynamic problem is a problem that requires input forces and initial conditions, and accelerations, positions, and velocities are then solved with respect to those input forces and initial conditions [116]. Some common dynamic models are summarised in Table 3 along with what friction phenomena can be explained by those.

\section{Physics-based models}

All the models previously described are empirical

Table 2 Steady-state models.

\begin{tabular}{ccc}
\hline Model name & Friction phenomena & Limitations \\
\hline $\begin{array}{c}\text { Stribeck } \\
\text { model }\end{array}$ & $\begin{array}{c}\text { Coulomb friction } \\
\text { Viscous friction }\end{array}$ & $\begin{array}{c}\text { No presliding and no } \\
\text { hysteresis accounted } \\
\text { for in this model }\end{array}$ \\
Sustin & Coulomb friction & Breaks down if the \\
model & Viscous friction & velocity exceeds a \\
& Static friction & certain threshold \\
\hline
\end{tabular}


Table 3 Dynamic models.

\begin{tabular}{ccccc}
\hline Model name & Seven-parameter & Karnopp (1985) [117] & Canudas et al. (1995) [118] & Dahl (1968) [119] \\
\hline $\begin{array}{c}\text { Pre-sliding } \\
\text { displacement }\end{array}$ & Yes & No & Yes & Yes \\
Coulomb friction & Yes & Yes & Yes & Yes \\
Viscous friction & Yes & Yes & Yes & Yes \\
Negative viscous & Yes & No & Yes & Yes \\
friction & Yes & Yes & Yes & Yes \\
Rising static friction & Yes & No & Yes & Yes \\
Dwell time & Yes & No & Yes \\
Frictional memory & Determining the & $\begin{array}{c}\text { A lot of phenomena are } \\
\text { not considered in the } \\
\text { Kimitations }\end{array}$ & $\begin{array}{c}\text { Discrepancies are observed } \\
\text { in certain experimental } \\
\text { results }\end{array}$ & Does not model the \\
nonibeck Effect
\end{tabular}

models. That is, they rely on empirical parameters, which can only be fit to the relevant parameters while accommodating the lack of information [120]. Furthermore, as empirical models do not account for the actual physics, the applicability of the model can become uncertain when conditions change. Other branches of friction models include physics-based models. Physics based models use robust scientific knowledge to formulate the model. This allows for physics-based models to be more accurate at representing the various conditions and more mechanisms can be considered compared to the normal empirical models [121]. However, even though physics-based models can capture all the friction related phenomena, they are in effect much harder to implement as they require an accurate account of all the relevant quantities, so missing data or unknown input data errors can create difficulties [122]. Some physics-based models are shown in Table 4.

\section{Concluding remarks}

A comprehensive review was provided in this paper on the different methodologies used to correlate friction and wear with friction noise and seeing how friction and wear would impact the sound pressure levels. This could either be done theoretically or experimentally. From a theoretical point of view, several

Table 4 Physics-based models.

\begin{tabular}{|c|c|c|}
\hline Model author & Advantages & Limitations \\
\hline $\begin{array}{l}\text { Emami et al. (2017) } \\
{[\text { [123] }}\end{array}$ & $\begin{array}{l}\text { Provides a good agreement with experimental results while } \\
\text { considering the effect of adhesion and shearing in the real } \\
\text { contact area along with hysteresis }\end{array}$ & Only valid for an intermediate range of velocities \\
\hline $\begin{array}{l}\text { Eriten et al. (2011) } \\
{[124]}\end{array}$ & $\begin{array}{l}\text { This model accounts for critical friction phenomena such as } \\
\text { stick-slip, modal frequencies and damping, and pre-sliding } \\
\text { friction. Furthermore, its physics-based nature gives it good } \\
\text { predictive capabilities }\end{array}$ & $\begin{array}{l}\text { The surface roughness parameters need to be } \\
\text { extracted along with surface height and asperity } \\
\text { distributions. The roughness parameters are also } \\
\text { not time-dependant }\end{array}$ \\
\hline $\begin{array}{c}\text { Dankowicz (1999) } \\
{[125]}\end{array}$ & $\begin{array}{l}\text { The model can predict dynamics which qualitatively agree with } \\
\text { other models. This model offers physics-based explanations } \\
\text { for the friction processes }\end{array}$ & $\begin{array}{l}\text { The values for the model parameters need to be } \\
\text { determined, along with appropriate choices for } \\
\text { the internal state variables. Determining those } \\
\text { initial values is a complex task }\end{array}$ \\
\hline $\begin{array}{l}\text { de Moerlooze et al. } \\
\text { (2010) [126] }\end{array}$ & $\begin{array}{l}\text { This model qualitatively agrees with experimental study and } \\
\text { accounts for normal creep, increasing static coefficient of } \\
\text { friction with increasing dwell time, pre-sliding hysteresis with } \\
\text { non-local memory, Stribeck and viscous effect, frictional lag, } \\
\text { stick-slip, and dynamical oscillations }\end{array}$ & $\begin{array}{l}\text { Wear and lubrication are not considered in this } \\
\text { model }\end{array}$ \\
\hline
\end{tabular}


friction models and wear models were developed separately. However, in all those cases, the acoustic emissions were not included in the purpose. The friction models that were developed as alternatives to Coulomb's model can be divided into two categories. They are either generally empirical models or physicsbased models. Empirical models are based on experimental evidence. They rely on defined parameters that are fit to match the conditions for which the model is developed. This allows for an accurate model restricted to the exact purpose it was developed for even if the underlying science is not understood. Physics-based models are general models that are created using general physics knowledge and thus can be applied everywhere. It is shown in this review that empirical models are still the model of choice in most friction problems and physics-based models are much less used. This is because they are still poorly understood, and their uses are still debatable. For example, de Moerlooze's model is a dry friction model that agrees with experimental results from a qualitative point of view, however, it still falls short as it does not include asperity wear or lubrication. The EPB model also presents many disadvantages. It is notably more demanding in terms of computational power (although with the increase in available technology, this problem can be diminished). Furthermore, the EPB model is unable to account for micro-displacements. The EPB model does need surface roughness measurements before it can be applied. This means that the surface roughness must be measured, the surface height data must be processed to describe the asperity-level geometry and the height distribution. Another major problem (that is not exclusive to the EPB model) is that it does not take the evolution of the micromechanics surfaces into question. As the surface roughness changes, the EPB model's predictions will no longer be accurate. This relates to the fact that those models do not include wear. However, no other experimental parameters are required provided that the material properties (Young's modulus, Poisson's ratio, and yield strength/hardness) are known. The EPB model is also highly dependent on the contact conditions. It is applicable for highly adhesive contacts at asperity scales. However, it is not applicable if the contacts have low adhesion. Empirical models are still the most widely used models to study friction-induced acoustic emissions. Furthermore, models studying noise and wear using lubrication are also not com. prehensive. As shown in the previous sections, even current physics-based models suffer from gaps that could be addressed in further research. For example, de Moerlooze's model does not take wear or lubrication into account. On the other hand, Emami's model is not valid for all velocities.

The wear models are similar in that they are all empirical and have been created to suit a particular engineering application. Still, the most widely used wear model to this date is Archard's model due to its relatively simple assumptions. However, the Archard's wear model has several shortcomings. For example, it is only valid for rough surfaces (with plastically deformed asperities). It is not valid for polymer surfaces (with elastically deforming asperities). In the case of the study of frictional noise due to wear, Archard's model is the one most widely used. Its assumptions are relatively simple. The wear is proportional to the path of friction, it is also proportional to the friction work force and finally, it is determined by the physical parameters of the process and the mechanical properties of the material. However, such model presents a lot of disadvantages that will impact its accuracy. This is due to a lack of methods to suitably estimate the wear coefficient needed for the model. The different combinations of materials, modes of operations, environments, etc., often leads to a discrepancy between the experimental results and those obtained by the calculations. Other limitations of Archard's wear model are that Archard's law is only applicable for rough surfaces (plastically deformed asperities). It is not applicable for softer surfaces like polymers (which have elastically deforming asperities). It can also be added that Archard's law does not consider material evolution. Materials that initially deform elastically, may start to deform plastically as the contact area and the subsurface hardness change. More advanced analytical wear models have also been developed. However, they are mainly focused on the adhesive wear mechanism and do not take friction noise into account. In all those models, the Hertzian contact laws are used, although they are modified to some extent to account for the specific application at hand (such as including the effect of adhesion). Furthermore, all the studies relating wear 
and frictional noise have been experimental. Numerical studies of wear do not take frictional noise into account. The same can be said with regard to friction models and noise. All studies correlating friction (be it surface roughness or friction coefficient) have been experimental, using Coulomb's law. Alternative and more advanced models, such as physics-based models have not been used regarding friction noise. Numerical studies analysing friction noise do not take wear into account. This means that there is no general analytical model that combines friction, wear, and acoustic emissions in a single model, suitable for a wide range of engineering applications as most currently used models are empirical and are thus only suited to the specific application for which they were modelled. A single analytical model including friction noise, friction coefficient, surface roughness, and wear volume during sliding wear could be a significant contribution to the existing literature and could also be adapted for use in a wide range of industrial applications as such a model would not be empirical by nature, and thus would not be confined to certain specific situations.

Open Access This article is licensed under a Creative Commons Attribution 4.0 International License, which permits use, sharing, adaptation, distribution and reproduction in any medium or format, as long as you give appropriate credit to the original author(s) and the source, provide a link to the Creative Commons licence, and indicate if changes were made.

The images or other third party material in this article are included in the article's Creative Commons licence, unless indicated otherwise in a credit line to the material. If material is not included in the article's Creative Commons licence and your intended use is not permitted by statutory regulation or exceeds the permitted use, you will need to obtain permission directly from the copyright holder.

To view a copy of this licence, visit http://creativecommons.org/licenses/by/4.0/.

\section{References}

[1] Khan M A, Cooper D, Starr A. BS-ISO helical gear fatigue life estimation and wear quantitative feature analysis. Strain 45(4): 358-363 (2009)
[2] Wang X C, Mo J L, Ouyang H, Wang D W, Chen G X, Zhu M H, Zhou Z R. Squeal noise of friction material with groove-textured surface: An experimental and numerical analysis. J Tribol 138(2): 021401 (2016)

[3] Soobbarayen K, Besset S, Sinou J J. A simplified approach for the calculation of acoustic emission in the case of frictioninduced noise and vibration. Mech Syst Signal Process 50-51: 732-756 (2015)

[4] Sergienko V P, Bukharov S N. Noise and Vibration in Friction Systems. Cham (Switzerland): Springer, 2014.

[5] Kirkup. The boundary element method in acoustics: A survey. Appl Sci 9(8): 1642 (2007)

[6] Harari I, Hughes T J R. A cost comparison of boundary element and finite element methods for problems of timeharmonic acoustics. Comput Methods Appl Mech Eng 97(1): 77-102 (1992)

[7] Hadfield M, Brebbia C A. Tribology and Design II. Southampton: WIT Press, 2012.

[8] Bayer R G. Selection and Use of Wear Tests for Metals. West Conshohocken (USA): ASTM International, 1976.

[9] Blau P J. Embedding wear models into friction models. Tribol Lett 34(1): 75-79 (2009)

[10] Park J Y, Salmeron M. Fundamental aspects of energy dissipation in friction. Chem Rev 114(1): 677-711 (2014)

[11] Blau P J. The significance and use of the friction coefficient. Tribol Int 34(9): 585-591 (2001)

[12] Akay A. Acoustics of friction. J Acoust Soc Am 111(4): 1525-1548 (2002)

[13] Pennestrì E, Rossi V, Salvini P, Valentini P P. Review and comparison of dry friction force models. Nonlinear Dyn 83(4): 1785-1801 (2016)

[14] Gnecco E, Meyer E. Fundamentals of Friction and Wear on the nano-scale. Berlin (Germany): Springer, 2015.

[15] Bowden F P, Tabor D, Palmer F. The friction and lubrication of solids. Am J Phys 19(7): 428-429 (1951)

[16] Persson B N J, Sivebaek I M, Samoilov V N, Zhao K, Volokitin A I, Zhang Z Y. On the origin of Amonton's friction law. J Phys: Condens Matter 20(39): 395006 (2008)

[17] Archard J F. Contact and rubbing of flat surfaces. J Appl Phys 24(8): 981-988 (1953)

[18] Bayer R J. Mechanical Wear Fundamentals and Testing. New York: CRC, 2004.

[19] Greenwood J A, Williamson J B. Contact of nominally flat surfaces. Proc R Soc Lond A 295(1442): 300-319 (1966)

[20] Briscoe B J, Tabor D. Friction and adhesion. Surface forces in friction and adhesion. Faraday Spec Discuss Chem Soc 2: 7-17 (1972)

[21] Myshkin N K, Kovalev A V. Adhesion and friction of polymers. In Polymer Tribology. Sujeet K Sinha, Ed. London: 
Imperial College Press, 2009: 3-37

[22] Johnson K L, Kendall K, Roberts A D. Surface energy and the contact of elastic solids. Proc $R$ Soc Lond A 324(1558): 301-313 (1971)

[23] Derjaguin B V, Muller V M, Toporov Y P. Effect of contact deformations on the adhesion of particles. $J$ Colloid Interface Sci 53(2): 314-326 (1975)

[24] Johnson K L, Greenwood J A. An adhesion map for the contact of elastic spheres. J Colloid Interface Sci 192(2): 326-333 (1997)

[25] Muller V M, Yushchenko V S, Derjaguin B V. On the influence of molecular forces on the deformation of an elastic sphere and its sticking to a rigid plane. J Colloid Interface Sci 45(1): 91-101 (1994)

[26] Le Bot A, Bou Chakra E. Measurement of friction noise versus contact area of rough surfaces weakly loaded. Tribol Lett 37(2): 273-281 (2010)

[27] Rapetto M P, Almqvist A, Larsson R, Lugt P M. On the influence of surface roughness on real area of contact in normal, dry, friction free, rough contact by using a neural network. Wear 266(5-6): 592-595 (2009)

[28] Spijker P, Molinari J F. The effect of loading on surface roughness at the atomistic level. Comput Mech 50: 273-283 (2012)

[29] Ghaednia H, Jackson R L. The effect of nanoparticles on the real area of contact, friction, and wear. J Tribol 135(4): 041603 (2013)

[30] Chey S K, Tian P, Tian Y. Estimation of real contact area during sliding friction from interface temperature. AIP Advances 6(6): 065227 (2016)

[31] Song B, Yan S. Relationship between the real contact area and contact force in pre-sliding regime. Chinese Physics $B$ 26(7): 074601 (2017)

[32] Rabinowicz E. Friction and Wear of Materials. 2nd edn. Hoboken (USA): John Wiley \& Sons, 2013.

[33] Kato K, Adashi K. Wear mechanisms. In Modern Tribology Handbook. Bharat Bhushan, Ed. Boca Raton: CRC Press, 2001: 273-300.

[34] Aghababaei R, Warner D H, Molinari J F. On the debris-level origins of adhesive wear. PNAS 114(30): 7935-7940 (2017)

[35] Nguyen Q S. Instability and friction. Comptes Rendus Mécanique 331(1): 99-112 (2003)

[36] Spurr R T. The ringing of wine glasses. Wear 4(2): 150-153 (1961)

[37] Yi Y B, Du S Q, Barber J R, Fash J W. Effect of geometry on thermoelastic instability in disk brakes and clutches. $J$ Tribol 121(4): 661-666 (1999)

[38] Le Bot A, Bou-Chakra E, Michon G. Dissipation of vibration in rough contact. Tribol Lett 41(1): 47-53 (2011)
[39] Kinkaid N M, O’Reilly O M, Papadopoulos P. Automotive disc brake squeal. J Sound Vib 267(1): 105-166 (2003)

[40] Müller M, Ostermeyer G P. A cellular automaton model to describe the three-dimensional friction and wear mechanism of brake systems. Wear 263(7-12): 1175-1188 (2007)

[41] Ostermeyer G P. On tangential friction induced vibrations in brake systems. In Non-Smooth Probl Veh Syst Dyn, Berlin: Springer, 2009: 101-111.

[42] Nishiwaki M, Abe K, Yanagihara H, Stankovic I, Nagasawa Y, Wakamatsu S. A study on friction materials for brake squeal reduction by nanotechnology SAE technical paper series. Warrendale, PA, USA: SAE International, 2008.

[43] Chen J S, Bogy D B. Mathematical structure of modal interactions in a spinning disk-stationary load system. $J$ Appl Mech 59(2): 390-397 (1992)

[44] Earles S E, Lee C K. Instabilities arising from the frictional interaction of a pin-disk system resulting in noise generation. J Eng Ind 98(1): 81-86 (1976)

[45] Earles S E, Chambers P W. Disc brake squeal noise generation: predicting its dependency on system parameters including damping. Int J Vehicle Des 8(4): 538-552 (1987)

[46] Crolla D A, Lang A M. Paper VII (i) brake noise and vibration - The state of the art. In Tribology Series. Dowson D, Ed. Amsterdam: Elsevier, 1991:165-174.

[47] Hervé B, Sinou J J, Mahé H, Jézéquel L. Analysis of squeal noise and mode coupling instabilities including damping and gyroscopic effects. Eur J Mech - A/solids 27(2): 141-160 (2008)

[48] Ibrahim R A. Friction-induced vibration, chatter, squeal, and chaos - part I: Mechanics of contact and friction. Appl Mech Rev 47(7): 209-226 (1994)

[49] Spurr R T. A Theory of brake squeal. Proceedings of the Institution of Mechanical Engineers: Automobile Division 15(1): 33-52 (1961)

[50] Ouyang H, Mottershead J E. A bounded region of disc-brake vibration instability. J Vib Acoust 123(4): 543-545 (2001)

[51] Ibrahim R A. Friction-induced vibration, chatter, squeal, and chaos-part II: Dynamics and modeling. Appl Mech Rev 47(7): 227-253 (1994)

[52] Oberst S, Lai J C S. Chaos in brake squeal noise. J Sound Vib 330(5): 955-975 (2011)

[53] Godfrey D. Friction oscillations with a pin-on-disc tribometer. Tribol Int 28(2): 119-126 (1995)

[54] Tabor, D. Friction, lubrication, and wear. In Mechanical Design Handbook. Rothbart H, Ed. New York: McGraw-Hill, 2006.

[55] Yoon E S, Kong H, Kwon O K, Oh J E. Evaluation of frictional characteristics for a pin-on-disk apparatus with different dynamic parameters. Wear 203: 341-349 (1997) 
[56] Emira N A, Mohamad H T, Tahat M S. Stick-slip detection through measurement of near field noise. Mech Eng Res, 3(3): 96-102 (2003)

[57] Popp K, Stelter P. Stick-slip vibrations and chaos. Phil Trans $R$ Soc Lond A 332(1624): 89-105 (1990)

[58] Abdo J, Tahat M, Abouelsoud A, Danish M. The effect of frequency of vibration and humidity on the stick-slip amplitude. Int J Mech Mater Des 6(1): 45-51 (2010)

[59] Chowdhury M A, Helali M. The effect of relative humidity and roughness on the friction coefficient under horizontal vibration. Open Mech Eng J 2(1): 128-135 (2008)

[60] Nam J H, Do H C, Kang J Y. Effect of groove surface on friction noise and its mechanism. Int J Precis Eng Manuf 18: 1165-1172 (2017)

[61] Bonnay K, Magnier V, Brunel J F, Dufrénoy P, De Saxcé G. Influence of geometry imperfections on squeal noise linked to mode lock-in. Int J Solids Struct 75-76: 99-108 (2015)

[62] Jolivet S, Mezghani S, El Mansori M, Vargiolu R, Zahouani H. Experimental study of the contribution of gear tooth finishing processes to friction noise. Tribol Int 115: 70-77 (2017)

[63] Yokoi M, Nakai M. A fundamental study on frictional noise: 1 st report, the generating mechanism of rubbing noise and squeal noise. Bull JSME 22(173): 1665-1671 (1979)

[64] Othman M O, Elkholy A H. Surface-roughness measurement using dry friction noise. Exp Mech 30(3): 309-312 (1990)

[65] Othman M O, Elkholy A H, Seireg A A. Experimental investigation of frictional noise and surface-roughness characteristics. Exp Mech 30(4): 328-331 (1990)

[66] Yokoi M, Nakai M. A fundamental study on frictional noise: (5th report, the influence of random surface roughness on frictional noise). Bull JSME 25(203): 827-833 (1982)

[67] Stoimenov B L, Maruyama S, Adachi K, Kato K. The roughness effect on the frequency of frictional sound. Tribol Int 40(4): 659-664 (2007)

[68] Ben Abdelounis H, Zahouani H, Le Bot A, Perret-Liaudet J, Tkaya M B. Numerical simulation of friction noise. Wear 271(3-4): 621-624 (2011)

[69] Jarvis R P, Mills B. Vibrations induced by dry friction. Proc Inst Mech Eng 178(1): 847-857 (1963)

[70] North M R. Disc brake squeal - A theoretical model. In MIRA Research Report, Nuneaton, UK,1972.

[71] Simo J C, Laursen T A. An augmented Lagrangian treatment of contact problems involving friction. Comput Struct 42(1): 97-116 (1992)

[72] Hirmand M, Vahab M, Khoei A R. An augmented Lagrangian contact formulation for frictional discontinuities with the extended finite element method. Finite Elem Anal Des 107:
28-43 (2015)

[73] Laursen T A, Simo J C. Algorithmic symmetrization of coulomb frictional problems using augmented lagrangians. Comput Methods Appl Mech Eng 108(1-2): 133-146 (1993)

[74] Oden J T, Martins J A C. Models and computational methods for dynamic friction phenomena. Comput Methods Appl Mech Eng 52(1-3): 527-634 (1985)

[75] Morgan F, Muskat M, Reed D W. Studies in lubrication: X. friction phenomena and the stick-slip process. $J$ Appl Phys 12(10): 743-752 (1941)

[76] Slavič J, Bryant M D, Boltežar M. A new approach to roughness-induced vibrations on a slider. J Sound Vib 306(3-5): 732-750 (2007)

[77] Kang J. Finite element modeling for stick-slip pattern of squeal modes in disc brake. $J$ Mech Sci Technol 28(10): 4021-4026 (2014)

[78] Stoimenov B L, Kato K. The relationship between frictional sound and lumps build-up at the contact interface in singlepass dry sliding between Aluminium pin and flat. In Tribology Series. Amsterdam: Elsevier, 2003: 159-164.

[79] Wang A Y, Mo J L, Wang X C, Zhu M H, Zhou Z R. Effect of surface roughness on friction-induced noise: Exploring the generation of squeal at sliding friction interface. Wear 402-403: 80-90 (2018)

[80] Chen Y, Shi X, Lu G, Zhou H, Yang Z. Reducing friction noise of M50 matrix composites by adding $\mathrm{Ti}_{3} \mathrm{SiC}_{2}$. Mater Res Express 6: 076510 (2019)

[81] Liu Y, Dowling A P, Shin H C. Effects of surface roughness on airframe noise. In the 12th AIAA/CEAS Aeroacoustics Conference, Cambridge, USA, 2006.

[82] G Chen. Friction-induced noise and vibrations: Diagnosis and prognosis. Adv Automob Eng 2(2): 1000e118 (2013)

[83] Nam J, Baek J, Do H, Kang J. Experimental investigation of friction noise on lubricated contact. J Mech Sci Technol 31(12): 5751-5760 (2017)

[84] Mo J L, Wang Z G, Chen G X, Shao T M, Zhu M H, Zhou $Z$ R. The effect of groove-textured surface on friction and wear and friction-induced vibration and noise. Wear 301(1-2): 671-681 (2013)

[85] Jibiki T, Shima M, Akita H, Hatano K. Friction noise caused by fretting under grease lubrication. In $2^{\text {nd }}$ World Tribology Congress, Vienna, Austria, 2001: 171-178.

[86] Chen G X, Zhou Z R, Kapsa P, Vincent L. Effect of surface topography on formation of squeal under reciprocating sliding. Wear 253(3-4): 411-423 (2002)

[87] $\mathrm{Hu} \mathrm{B}$. Friction and wear of automotive and aircraft brakes. In ASM Handbook. Totten G E, Ed. Materials Park: ASM International, 2017: 969-983. 
[88] Jacko M G, Tsang P H S, Rhee S K. Automotive friction materials evolution during the past decade. Wear 100(1-3): 503-515 (1984)

[89] Newcomb T P, Spurr R T. Friction materials for brakes. Tribology 4(2): 75-81 (1971)

[90] Rhee S K. Wear mechanisms for asbestos-reinforced automotive friction materials. Wear 29(3): 391-393 (1974)

[91] Duarte M, Vragovic I, Molina J M, Prieto R, Narciso J, Louis E. 1/f noise in sliding friction under wear conditions: The role of debris. Phys Rev Lett 102(4): 045501 (2009)

[92] Jibiki T, Shima M, Akita H, Tamura M. A basic study of friction noise caused by fretting. Wear 251(1-12): 1492-1503 (2001)

[93] Eriksson M, Lord J, Jacobson S. Wear and contact conditions of brake pads: Dynamical in situ studies of pad on glass. Wear 249(3-4): 272-278 (2001)

[94] Österle W, Griepentrog M, Gross T, Urban I. Chemical and microstructural changes induced by friction and wear of brakes. Wear 251(1-12): 1469-1476 (2001)

[95] Boness R J, McBride S L. Adhesive and abrasive wear studies using acoustic emission techniques. Wear 149(1-2): 41-53 (1991)

[96] Boness R J, McBride S L, Sobczyk M. Wear studies using acoustic emission techniques. Tribol Int 23(5): 291-295 (1990)

[97] Benabdallah H S, Aguilar D A. Acoustic emission and its relationship with friction and wear for sliding contact. Tribol T 51(6): 738-747 (2008)

[98] Meng H C, Ludema K C. Wear models and predictive equations: Their form and content. Wear 181-183: 443-457 (1995)

[99] Yadav G, Tiwari S, Rajput A, Jatola R, Jain M L. A review: Erosion wear models. In International Conference on Emerging Trends in Mechanical Engineering, Bhopal, India, 2016: $150-154$.

[100] Barwell F T. Wear of metals. Wear 1(4): 317-332 (1958)

[101] Zmitrowicz A. Wear debris: A review of properties and constitutive models. $J$ Theor App Mech-Pol 43(1): 3-35 (2005)

[102] Shen X, Cao L, Ruyan L. Numerical simulation of sliding wear based on archard model. In 2010 International Conference on Mechanic Automation and Control Engineering, Wuhan, China, 2010: 325-329.

[103] Hassan A K F, Mohammed S. Artificial neural network model for estimation of wear and temperature in pin-disc contact. Universal Journal of Mechanical Engineering 4(2): 39-49 (2016)

[104] Rhee S K. Wear equation for polymers sliding against metal surfaces. Wear 16(6): 431-445 (1970)
[105] Archard J F, Hirst W. The wear of metals under unlubricated conditions. Proc R Soc Lond A 236(1206): 397-410 (1956)

[106] Archard J F. The temperature of rubbing surfaces. Wear 2(6): 438-455 (1959)

[107] da Silva C R Á Jr, Pintaude G Jr. Uncertainty analysis on the wear coefficient of Archard model. Tribol Int 41(6): 473-481 (2008)

[108] Quinn T F J. Oxidational wear. Wear 18(5): 413-419 (1971)

[109] Öqvist M. Numerical simulations of mild wear using updated geometry with different step size approaches. Wear 249(1-2): 6-11 (2001)

[110] Mukras S, Kim N H, Sawyer W G, Jackson D B, Bergquist L W. Numerical integration schemes and parallel computation for wear prediction using finite element method. Wear 266(7): 822-831 (2009)

[111] Savio G, Meneghello R, Concheri G. A surface roughness predictive model in deterministic polishing of ground glass moulds. Int J Mach Tools Manuf 49(1): 1-7 (2009)

[112] Fillot N, Iordanoff I, Berthier Y. Wear modeling and the third body concept. Wear 262(7-8): 949-957 (2007)

[113] Stachowiak G, Batchelor A W. Engineering Tribology. Oxford (UK): Butterworth-heinemann, 2013.

[114] Mate C M. Tribology on The Small Scale: A Bottom-up Approach to Friction, Lubrication and Wear. Oxford (UK): Oxford University Press, 2008.

[115] Olsson H, Åström K J, Canudas de Wit C, Gäfvert M, Lischinsky P. Friction models and friction compensation. Eur J Control 4(3): 176-195 (1998)

[116] Dupont P E. Friction modeling in dynamic robot simulation. In IEEE International conference on Robotics and Automation. Cincinnati, USA, 1990: 1370-1376.

[117] Karnopp D. Computer simulation of stick-slip friction in mechanical dynamic systems. J Dyn Syst Meas Control 107(1): 100-103 (1985)

[118] Canudas de Wit C, Olsson H, Astrom K J, Lischinsky P. A new model for control of systems with friction. IEEE Trans Autom Control 40(3): 419-425 (1995)

[119] Dahl P R. A solid friction model. In Technical Report TOR-0158(3107-18), El Segundo, USA, 1968.

[120] Adams H D, Williams A P, Xu C G, Rauscher S A, Jiang $\mathrm{X}$ Y, McDowell N G. Empirical and process-based approaches to climate-induced forest mortality models. Front Plant Sci 4: 438 (2013)

[121] Al-Bender F. Fundamentals of friction modelling. In Proceedings, ASPE Spring Topical Meeting on Control of Precision Systems, Cambridge, USA, 2010: 117-122.

[122] Nachtergaele J, Poesen J, Steegen A, Takken I, Beuselinck L, Vandekerckhove L, Govers G. The value of a physically 
based model versus an empirical approach in the prediction of ephemeral gully erosion for loess-derived soils. Geomorphology 40(3-4): 237-252 (2001)

[123] Emami A, Khaleghian S, Su C, Taheri S. Physics-Based friction model with potential application in numerical models for tire-road traction. In Proceedings of the ASME 2017 Dynamic Systems and Control Conference. Tysons, USA, 2017.

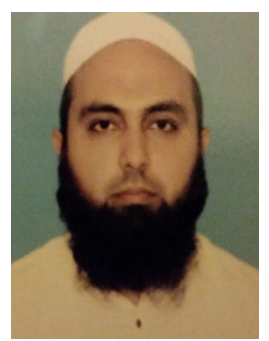

Muhammad KHAN. Upon receiving his bachelors in mechanical engineering from NEDUET Karachi in 2002, he joined Technology Promotion Internationals (Head Quarter: Maryland USA) for more than 3 years in the capacity of a Research Engineer. In these years, he was involved in fault diagnosis of defense applications mainly funded by General Dynamics including US Marines Expeditionary Fighting Vehicle (EFV) and Medium Tactical Vehicle Replacement (MTVR). In 2006, he went to The University of Manchester for his master's degree leading to doctoral studies and completed his Ph.D. degree in 2008 with more than 12 publications in the area of fatigue of gear assemblies. Later, he joined University of Hertfordshire as a post-doctoral research associate in 2009 for two years. Where he worked on a UK MOD project related to aerospace transmission fatigue diagnosis partnered with the

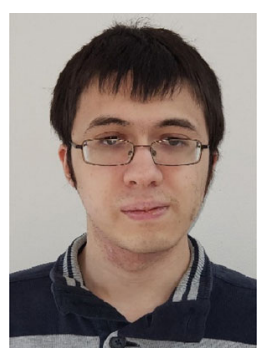

Kevin LONTIN. He received his B.Sc. degree in physics in 2016 from the University of Bath. He then received his M.Sc. degree in advanced mechanical engineering
[124] Eriten M, Polycarpou A A, Bergman L A. A physics-based friction model and integration to a simple dynamical system. J Vib Acoust 134(5): 051012 (2012)

[125] Dankowicz H. On the modeling of dynamic friction phenomena. ZAMM 79(6): 399-409 (1999)

[126] de Moerlooze K, Al-Bender F, Van Brussel H. A generalised asperity-based friction model. Tribol Lett 40(1): 113-130 (2010)

University of Manchester, University of Warwick and QinetiQ. He briefly taught mechanical engineering at Universiti Teknologi Petronas (Malaysia) as a lecturer in 2011 and in the same year he then joined National University of Sciences and Technology (NUST) Pakistan as an assistant professor. At NUST, he established a Root Cause Failure Analysis (RCFA) center and being the Head of Postgraduate Programme started a new master's in the area of computational mechanics.

He is involved in the industrial and the academic research for the last 15 years. His current areas of interest are: Fatigue of metallic structures and machine components, experimental evaluation of damage and prediction of useful life, non destructive testing methodologies, and tribological phenomenon in mechanical contacts. $\mathrm{He}$ is a Chartered Engineer (CEng) and a full member of Institute of Mechanical Engineers (IMechE) UK.

from the University of Cranfield in 2018. He is currently studying his Ph.D. degree at the University of Cranfield. His current research interests are mainly about friction and wear of materials. 